\title{
Analysis and optimization of energy absorbers of sandwich tubes with aluminium foam core under lateral loading
}

\author{
A. Baroutaji ${ }^{1}$, M.D.Gilchrist ${ }^{2}$, D.Smyth ${ }^{3}$, A.G. Olabi ${ }^{3}$ \\ (1)- School of Mechanical and Manufacturing Engineering, Dublin City University, Glasnevin, Dublin 9, Ireland \\ Email:ahmad.baroutaji2@mail.dcu.ie \\ (2)- School ofMechanical \& Materials Engineering, UniversityCollegeDublin, Dublin4, Ireland \\ (3)- Institute of Engineering and Energy Technologies, School of Engineering, University of the West of Scotland, \\ Paisley,PA12BE,UnitedKingdom.
}

\begin{abstract}
:
In this paper, the sandwich tubes, which consist of thin-walled circular tubes with aluminium foam core, were proposed as energy absorption devices. The sandwich tubes were laterally crushed under quasi-static loading conditions. Detailed finite element model, validated against existing experimental results, was developed using the explicit code (ANSYS-LSDYNA) to assess the energy absorption responses and deformation modes. Response surface methodology (RSM) was employed in parallel with the finite element models to perform both parametric studies and multi-objective optimization in order to establish the optimal configuration of the sandwich tube. Sampling designs of the sandwich tubes were constructed based on a D - optimal design of experiment (DOE) method. Factorial analysis was performed using the DOE results to investigate the influences of the geometric parameters on the responses of sandwich tubes. In addition, multi-objective optimization design (MOD) of the sandwich tubes is carried out by adopting a desirability approach. It was found that the tube with a minimum diameter of the inner layer and a maximum foam thickness are more suitable for use as energy absorbing components.
\end{abstract}


Keywords: Sandwich tube, Energy absorbing systems, lateral collapse, ANSYSLSDYNA, Aluminium foam, Design of Experiment, factorial analysis.

\section{Introduction:}

Empty thin-walled tubes crushed laterally have received a considerable amount of attention in the last four decades [1-11]. All investigations showed that the collapse mode of these components consisted of plastic bending conforming to the plastic hinge model of the lateral collapse of tubes. Since the strain energy is localised around the plastic hinges, the dissipation of energy through the lateral collapse is not structurally efficient [12]. Therefore, to improve the energy absorption performance, foam-filled components have been proposed. A light material such as a honeycomb, cork, wood, foam, and rubber can be used as a filler material in thin-walled components. Using filler materials along with thin-walled component enhances the absorption of energy of the whole structure. The structural and weight efficiencies of these structures make them practical for engineering applications. Using foams as filler material in thin-walled tubes provides several potential benefits for energy absorption. Much research has been performed to investigate crush and energy absorption responses of foam-filled thin-walled tubes under axial loading. Examples include foam-filled circular tubes [13-16], foam-filled square tubes [17-20], foamfilled conical tubes [21-24], foam-filled tapered rectangular tubes [25, 26] and foamfilled hat sections $[27,28]$.

Overall, researches on the collapse behaviour and energy absorption response of foam-filled tubes (either rectangular or circular cross-section) under lateral loading have been less reported in the literature. Considering the importance of such 
structures, a few numbers of studies have been performed to investigate the collapse behaviour and energy absorption response of foam-filled structures under lateral loading [12, 29-32].

In the past, the study and analysis of energy absorbing devices were performed by using empirical and analytical techniques. Nowadays, traditional techniques have been complemented with the finite element method (FEM), which is a very powerful tool particularly for performing parametric studies. In addition to FEM, an alternative approach known as factorial design is also employed by the researchers to investigate the responses of energy absorbing systems. It is considered as an important facility for evaluating the main and interaction effects of the various parameters on the energy absorption responses. In general, the factorial analysis of energy absorbing structures can be performed by choosing a number of design variables (factors), which can pertain to the material, geometry, or loading parameters. Then specific levels for each variable are chosen, and the tests are run, either by experiments or simulations, using all the possible combinations and the corresponding design responses are calculated. The main and interaction effects can be specified accordingly. Main effects refer to change in the system's response with change in one factor (variable). The interaction effect occurs when the response is affected by the settings of two factors. Normally, the factorial analysis is carried out by using statistical based approach called design of experiments (DOE). The DOE technique provides the ability to construct surrogate models such as Response Surface (RS) models which relate the crushing and energy absorption responses to design variables. These surrogate models can then be used to analyze the responses of the energy absorbing structure and also to perform multi-objective optimization design (MOD) of it. The optimal design can be achieved by using the surrogate 
models in the optimization algorithm, such as the multi-objective particle swarm optimization (MOPSO) algorithm and desirability approach. Many studies have used surrogate models with the optimization algorithm to seek an optimal design for empty and foam-filled thin-walled tubes under pure axial [20,33-38], bending [40,41], and oblique loads [42].

Much of the research on the optimization of foam-filled energy absorption structures has focused on those axially crushed devices. However, the laterally crushed sandwich tubes have received no attention.

In the present paper, numerical investigations into the quasi-static lateral collapse of sandwich tube systems have been performed. The FE model has been developed and validated against existing experimental results in the literature. An experimental design was created based on D-optimal design. The outer layer diameter $\left(\mathrm{D}_{\mathrm{o}}\right)$, the outer layer thickness $\left(t_{0}\right)$, the inner layer diameter $\left(D_{i}\right)$, and the inner layer thickness $\left(t_{i}\right)$ were applied as independent input variables. The specific energy absorption (SEA) and collapse load (F) were selected as the design responses. Factorial study was performed to investigate the main and interactive effects of geometric parameters on SEA and F. In addition, MOD study was performed to seek an optimal configuration for sandwich tube systems.

\section{Numerical simulations}

\subsection{Material properties:}

As described by Fan et al [29], the sandwich tubes were prepared by cutting the outer, inner and foam core separately and then assemble these three components together. These components were then adhered together by using thixotropic epoxy liquid glue (FORTIS AD825). The material of outer and inner layers is aluminium 
alloy AA6060T5. Foam core was prepared by using ALPORAS ${ }^{\circledR}$ aluminium foam. The mechanical properties of both AA6060T5 and ALPORAS ${ }^{\circledR}$ (Table 1) are the same as reported by [30]. As the loading type is quasi-static, the strain-rate effects are not taken into account in the finite element modelling.

\subsection{FE model}

The commercial explicit FE code ANSYS-LSDYNA [45] was used for all finite elements modelling of sandwich tubes. Figure 1 shows the finite element mesh of the half model of the sandwich tube. A 3D-structural solid element (solid 164), which has eight nodes with large strain, large deflection, and plasticity capabilities was used to model the foam core. A crushable foam model was used to define the ALPORAS ${ }^{\circledR}$ aluminium foam material. The moving top plate was modelled as rigid body and constrained to move vertically along the y-axis. The bottom plate was also modelled as a rigid entity, with all rotations and translations being fixed. Outer and inner aluminium tubes were modelled by using shell element (SHELL163) with Belytschko-Tsay element formulation. A bilinear kinematic hardening material model was employed to define the material behaviour of the outer and inner aluminium tubes. The mechanical properties of the foam and the aluminium tubes were the same as those listed in Table 1. An automatic 'surface to surface' contact type was used to define the contact between the outer tube and all rigid bodies. The perfect bonding between three components of the sandwich system was modelled by using a tied 'node to surface' contact type between the foam core and both the outer and the inner tubes. The mesh convergence analysis was performed to find the optimum mesh size. It was found that element sizes of $2 \mathrm{~mm}, 5 \mathrm{~mm}$, for aluminium layers and ALPORAS ${ }^{\circledR}$ foam respectively, were able to produce accurate results. All 
models were subjected to symmetry boundary conditions in order to reduce simulation solving times.

The quasi-static loading was simulated by defining the motion of a moving rigid body through applying a prescribed velocity to it. The velocity was ramped up in a ramping time of $t_{R}=12.5(\mathrm{~ms})$ (this value provided acceptable results), and then followed by a constant velocity of $2 \mathrm{~m} / \mathrm{sec}$ for the remainder of the loading time $\left(\mathrm{t}_{\mathrm{T}}\right)$ as shown in Figure 2.

In general, explicit codes are mostly used to simulate the impact events with high velocities. The quasi-static problems can also be simulated by explicit codes with reasonable computing time and accuracy as addressed by Refs [43, 44].

To confirm that the quasi-static solution is maintained over the duration of loading, the ratio of the total kinetic energy (KE) to the total internal energy (IE) should be less than $5 \%$ over the period of the crushing process and also the crushing forcedisplacement response should be independent of the loading velocity. To this end, Figure 3 and Figure 4 were generated for the present FE model. Clearly, it can be seen from Figure 3 that the ratio of the total kinetic energy to the total internal energy is less than 5\%. It should be noted that in the current FE model, the moving rigid body has no mass and so the only kinetic energy is due to the motion of the sandwich tube. Also, the total internal energy is equal to the plastic deformation energy of the sandwich tube, where the rigid bodies do not deform and so do not reserve any internal energy. The Figure 4 shows that the load-deflection curve response is independent of the loading velocity so that the dynamic effects are negligible. Ahmad [43] and Santoes et al. [18] used the same approach in their studies. 


\subsection{Validation of FE model}

To verify the validity of FE model of sandwich tubes, the numerical results were validated against experimental results presented by Fan et al [29]. The experimental data were obtained from a study carried out by Fan et al [29] on a sandwich tube with an outer layer diameter of $150.2 \mathrm{~mm}$, an outer layer thickness of $3.28 \mathrm{~mm}$, an inner layer diameter of $127.1 \mathrm{~mm}$, an inner layer thickness of $2.69 \mathrm{~mm}$, and a width of $50 \mathrm{~mm}$. Figure 5 shows the numerical and experimental force-deflection curves for the compression of the sandwich tube under quasi-static loading. The results show a reasonable agreement between the existing experimental results and present FE predictions. A slight under-prediction was offered by the FE results in the post collapse stages. This under-estimation is due to tangential slippage existed in the lower region of sandwich tube which increased the contact area of out tube during the experiment [29].

The collapse stages of sandwich tube under lateral loading are presented in Figure 6. It can be seen that the outer layer, inner layer and foam core were deformed simultaneously. The same phenomena were also reported by [29].

Overall, the FE results showed excellent agreement with experimental results for lateral collapsing of sandwich tubes under quasi-static lateral loading.

\subsection{Numerical results and discussion}

The force-deflection response of the sandwich under quasi-static lateral loading is displayed in Figure 5. The sandwich tube was compressed by $87 \mathrm{~mm}$ in order to avoid overloading and inner layer self-contact. It can be seen that, at the early stages of deformation, the crush force was increased linearly with the displacement. This 
stage is called the elastic phase. After the elastic phase, the force started to increase gradually as the displacement increased. This behaviour is due to the strain hardening characteristic of the aluminium tubes, the geometric change of the system, and the hardening or densification of the foam core during crushing. The Figure 7 plots the plastic strain energy for each individual component of the sandwich tube. It can be seen that the greater contribution to the energy dissipated by the system was due to the foam core. The foam dissipated around $44 \%$ of the total energy dissipated at a displacement of $87 \mathrm{~mm}$. The ratio of energy dissipated by the outer and the inner tubes was $31.7 \%$ and $24.4 \%$ respectively. The Figure 8 shows the deformation history of the sandwich tube, illustrating how the three components deform simultaneously. A symmetric collapse mode about both the vertical and horizontal planes was recorded.

\section{Response surface models}

The energy absorption behaviour of the structures under various loading conditions is one of highly nonlinear mechanics problems which are very complicated to establish mathematical relations for their responses. Recently, design of experiment (DOE) method was applied by the researchers [20, 33-42] to construct surrogate models such as Response Surface (RS) models which relate the, crushing and energy absorption responses to design variables for analysis and optimization purposes. The design variables could be one or more of the geometrical parameters, material parameters and loading parameters. The advantage of employing the (RSM) as an analysis and optimization tool in the field of energy absorption systems is that the energy absorbing behaviour of a structure in a particular design space can be identified through performing a limited number of experiments at the sampling 
design points of the design space. The sampling design points are determined using one of the many designs of experiments (DOE) techniques. The experiments can be physical tests (real test) or numerical simulations based on validated FE model. In this section, integration of Finite Element Modelling (FEM) and the Response Surface Method (RSM) for the Design of Experiment (DOE) was used to model the relationship between the energy absorption responses and the geometrical parameters of the sandwich tube within a particular range of these geometrical parameters (specific design space). Statistical software package, Design-Expert 8, was used to create the sampling design points and to apply RSM on the results of the numerical model described and validated earlier in section 2.2 and section 2.3 respectively. The models developed in this section are useful formulations which relate the crashworthiness responses to the geometrical parameters. These developed functions allow prediction of the energy absorption responses of laterally crushed sandwich tubes, based on their geometry parameters. In addition, these formulations can provide engineering designers with an initial estimate of the energy absorption responses for the sandwich tube of given dimensions. Also, the formulations provide a guide as to which parameters have the most influence on the energy absorption responses. Furthermore, the RS models can be used for structural optimization after verifying their accuracy as will be shown in section 5. Figure 9 displays the flow chart which explains the steps for constructing the RS models.

\subsection{Sampling design points}

Different methods were offered by Design-Expert to construct the sampling design points such as factorial, Box-Behnken, composite, D-optimal. In this study, a Doptimal design was used to construct the experimental design. The D-optimal design 
is widely used in crashworthiness optimization [46-48]. This Design can reduce the number of required sample points for constructing the RS models with good quality. Also, D-optimal design is the highly efficient method among all the factorial design methods particularly if the design space is constrained. Four independent variables were selected: the outer layer diameter $\left(D_{0}\right)$, the outer layer thickness $\left(t_{0}\right)$, the inner layer diameter $\left(\mathrm{D}_{\mathrm{i}}\right)$, and the inner layer thickness $\left(\mathrm{t}_{\mathrm{i}}\right)$, resulting in 25 tests to be performed. Logically, the diameter of the outer layer will always be larger than the inner diameter, so a multi-linear constraint was defined in the design. The constraint bounds are based on the desire to have moderate values for the thickness of foam core as the very thick foam core might change the collapse pattern of the sandwich tube [31]. Table 2 presents the geometrical variables levels and constraints used in this analysis. The design variables limits were selected to cover the typical range of sandwich tube sizes that can be used in crashworthiness applications, such as the crush boxes used in car bumpers. The specific energy absorption (SEA) and collapse load $(\mathrm{F})$ were selected as the design responses.

The specific energy absorption capacity (SEA) is the energy absorbed per unit mass, and is given by:

$$
\mathrm{SEA}=\frac{\mathrm{E}}{\mathrm{m}}
$$

Where, m: is the mass of the sandwich tube, E: is the energy absorption capacity which can be measured by calculating the area under the force-deflection response of the sandwich tube, as shown in Figure 10 . 
The collapse load of the sandwich tube is the force required to cause permanent deformation in the tube. Explanation of design responses and design variables is displayed in Figure 10.

Detailed FE models were created for the sandwich tubes representing the sampling design points. The simulation tests were conducted for the different combinations of independent variables and the responses (SEA, F) were calculated.

The SEA for each tube was calculated up to $60 \%$ of the mean diameter (mean diameter $\left.=\frac{D_{0}+D_{i}}{2}\right)$. This value was carefully selected to avoid the undesirable behaviours of the system overloading and the extreme plastic strains which might lead to a structural failure and ineffective energy dissipation process.

For the collapse load $(\mathrm{F})$ response, it was captured at the time when the sandwich tube began to be deformed plastically.

Table 3 shows different combinations of design variables with corresponding design responses.

\subsection{Development and accuracy of the RS models}

A step-wise regression method was used to fit the RS model to the numerical results and to identify the relevant model terms. The step-wise regression method is recommended because it eliminates the insignificant model terms automatically from the RS model. The statistical significance of the developed models and each term in the regression equation was inspected using statistical measures to achieve the best fit. From analysing the measured responses by the Design-expert software, the summary output of best fit indicates that quadratic models are statistically recommended for the specific energy absorption (SEA) and collapse load (F). The 
analysis of variance (ANOVA) methodology was employed by the software to check the adequacy of the developed models. The ANOVA tables summarise the analysis of variance for response and show the significant model terms and the adequacy measures. Table 4 shows the analysis of variance ANOVA results generated by the model of the SEA response. The model's F-value of 175.60 implies that this model is significant. A p-value of 0.0001 suggested that there is only $0.01 \%$ chance the Fvalue could occur due to noise. The predicted R-squared of 0.97 is in reasonable agreement with the adjusted R-squared of 0.98 . It can be seen that the predicted Rsquared and the adjusted R-squared are within 0.20 of each other, which corresponds with what it is reported in [49]. High R-squared values suggest that there is a statistically significant correlation between the factors and the response. The Adeq Precision value measures the signal to noise ratio. The adequate precision ratio above 4 indicates adequate model discrimination [49]. In this model, the adequate precision was found to be 45.12 , indicating an adequate signal. This means that the model can be used to navigate the design space.

The analysis of variance indicated that the following terms were the most significant terms associated with specific energy absorbed:

1- The first order effect of the outer layer diameter (Do), the outer layer thickness (to), the inner layer diameter (Di), and the inner layer thickness (ti).

2- Second order effect of the inner layer thickness (ti).

3- The two level interaction effects between the outer layer diameter and thickness (Do $\times$ to), the outer layer diameter and inner layer thickness $($ Do $\times$ ti), and the outer layer thickness and inner layer diameter (to $\times \mathrm{Di})$. 
The resulting SEA can be modelled by the final equation produced by the model given in Table 4.

The $\mathrm{F}$ values from the ANOVA table can be used to rank the influence of the independent variables and their interactions on the specific energy absorbed. The order of the factors influencing the SEA was as follow:

$\mathrm{C}>\mathrm{A}>\mathrm{BC}>\mathrm{AB}>\mathrm{AD}>\mathrm{D}>\mathrm{D}^{2}>\mathrm{B}$

The values of the SEA were found to be highly predictable according to the model as seen in Figure 11. Most of the SEA values lie on the line of best fit of the predicted results

The analysis of variance (ANOVA) of the F response is presented in Table 5. The model F-value of 340.59 indicates that the model is significant. A p-value of 0.0001 suggests that there is a low chance that the F-value was due to noise. The "Pred RSquared" of 0.9787 is in reasonable agreement with the "Adj R-Squared" of 0.9861. The adequate precision ratio was found to be 49.7 , which is significantly higher that the threshold of 4 . This means that the model had very little noise. Therefore, the model can be used to navigate the design space. The model showed that the most significant terms affecting the crush load are as follow:

1- The first order effect of the layer diameter (Do), the outer layer thickness (to), the inner layer diameter (Di) and the inner layer thickness (ti).

2- Two level interaction effect between the outer layer diameter and inner layer thickness (Do $\times$ ti).

The final mathematical models in terms of the actual factors as determined by the design expert software are presented in Table 5. 
The order of impact of the factors on the crush force can be established through comparing the magnitude of the F-values as follows: $\mathrm{C}>\mathrm{A}>\mathrm{D}>\mathrm{B}>\mathrm{AD}$.

Figure 12 illustrates that there is good agreement between the actual and the predicted values of the crush force. It can be seen that the residuals tend to be close to the diagonal line, which suggests that the RS models are valid.

\section{Factorial analysis}

The essential design information for sandwich tubes used as energy absorbing structures can be obtained through performing a factorial analysis. To this end, the DOE results were employed to study the effects of geometrical parameters on the energy absorption responses of sandwich tubes.

\subsection{Effect of geometrical factors on SEA response}

Figure 13 and Figure 14 plot the interaction effects of Do-to and Do-ti on the SEA response respectively. The interaction effect occurs when the effect of a first factor on the response depends on the setting of the second factor. It can clearly be seen that an increase in the diameter of the outer layer caused an increase in the specific energy absorbed. The outer layer diameter had more influence on the SEA of the sandwich tubes with a thinner outer layer, as shown in Figure 13. Figure 13 also shows that the SEA decreased with increasing thickness of the outer layer. Figure 14 demonstrates that the effect of Do on SEA depended also on the value of the inner layer thickness, with more influence of Do seen in the tubes with a thinner inner layer. Similarly, it can also be noted from Figure 14 that the SEA increased as the inner layer thickness increased. Figure 15 presents the interaction effect of Di-to on 
the SEA of the sandwich tube. From this figure, it is clear that the SEA decreased with an increase of the inner layer diameter. The rate of decrease of the SEA with Di decreased in tubes that had thicker outer layers. In general, it was concluded that the SEA increased as the thickness of the foam core increased (an increase of Do and a decrease of $\mathrm{Di}$ ). This trend is probably due to the higher amount of energy being absorbed by the foam core and dissipated by the system as a whole, as described earlier in Figure 7. As such, the thickness of the foam core played an essential role in controlling the value of SEA. Finally, Figure 16 shows the variation of SEA with Do and ti. It can be seen that the maximum value of SEA was recorded for the tube that had the maximum value of foam thickness and the minimum value of the inner layer diameter.

To further assess the energy dissipation characteristic of sandwich tubes, the contribution of each individual component of the sandwich tube, i.e. aluminium tubes and foam core, in the energy dissipation process was investigated.

Figure 17 shows the plastic strain energy for each individual component of the sandwich tubes for all design points. It can be seen that the partitions of dissipated energy in each sandwich tube are dissimilar. This is due to fact that the plastic strain energy of each component in the sandwich tube depends on the geometric parameters, i.e. diameter, thickness, and width, of this component. In general, it is clear from this figure that the increase of foam thickness leads to a decrease in the contribution of plastic energy for both inner and outer tubes. It is interesting to note that in some particular experiments where the foam cores are not thick enough and the diameter of aluminium layers are small, the plastic strain energy of tubes is higher than that of foam core, as it can be seen for runs 7 and 8 . 


\subsection{Effect of geometrical factors on $F$ response}

The variation of the collapse load with the diameter of the outer tube and the thickness of the inner tube for a constant $t_{o}$ of $2.25 \mathrm{~mm}$ and constant $\mathrm{Di}$ of $80 \mathrm{~mm}$ is presented in Figure 18. Clearly, it can be seen that the collapse load increased as the diameter of the outer layer increased.

Figure 19 shows the variation of the collapse load with the diameter of the inner tube and the thickness of the outer tube. From this figure, it is clear that the collapse load increased with a reduction of inner layer diameter. This increase of the collapse load with increasing outer diameter Do and decreasing inner diameter Di, was due to the higher amount of foam across the section of the tube, which effectively increased the lateral stiffness of the sandwich tube and hence increased the load required to initiate collapse. The Figure 18 and Figure 19 also show the effect of aluminium layers thicknesses on the collapse load of the sandwich tube. Obviously, it can be seen that the collapse load increased as the thicknesses increased. This trend was due to the increase of the stiffness of the outer and inner layer with an increase of thickness.

Finally, as a summary, the minimum value of collapse load occurred in the case of the tube which had the minimum values of foam thickness and layers thicknesses.

\section{Multi-objective optimization design (MOD)}

In spite of the factorial analysis (section 4) has addressed the effect of various parameters on the crashworthiness behaviour of the sandwich tubes, it is still unknown what is the best design for the sandwich tubes under the lateral loading. Generally, as part of the analysis of energy absorbing structures, the various responses being investigated need to be optimized. The design optimization of the 
various energy absorbing structures should be addressed within a multi-objective framework. The merit of multi-objective optimization design is that it provides a deep understanding of the interaction between the different crashworthiness criteria [50]. Also, MOD approach is more suitable for most of real-life applications which need to consider several objectives simultaneously [51].

\subsection{Description of optimization problem}

As a general rule in crashworthiness design of energy absorbing structures, the structure with good crashworthiness is able to absorb as high energy as possible with relatively as low crushing force as possible. So the SEA was selected as the first objective and maximized while the collapse load (F) was taken as another objective and minimized. Minimizing the collapse load in the crashworthiness design is based on human safety issue as the large collapse load often leads to a high deceleration and may cause serious injury or even death of passengers inside the survival space. Also, minimizing the collapse force ensure that the absorber does not transmit too much force to the other parts of the protected structure.

Therefore, the optimization problem can be written as the following multi-objective optimization form

$$
\left\{\begin{array}{c}
\text { Maxmize } \mathrm{f} 1=\mathrm{SEA}(\mathrm{x}) \\
\text { Minmize } \mathrm{f} 2=\mathrm{F}(\mathrm{x}) \\
\text { s.t } \quad \mathrm{x}^{\mathrm{l}} \leq \mathrm{x} \leq \mathrm{x}^{\mathrm{u}}
\end{array}\right.
$$

Where $\mathrm{x}=\left(\mathrm{x}_{1}, \mathrm{x}_{2} \cdots \mathrm{x}_{\mathrm{k}}\right)$ are the vector of geometrical parameters, $\mathrm{x}^{\mathrm{L}}=\left(\mathrm{x}^{\mathrm{L}}{ }_{1}, \mathrm{x}_{2}^{\mathrm{L}}, \cdots\right.$ , $\left.\mathrm{x}_{\mathrm{k}}^{\mathrm{L}}\right)$ and $\mathrm{x}^{\mathrm{U}}=\left(\mathrm{x}_{1}^{\mathrm{U}}, \mathrm{x}_{2}^{\mathrm{U}}, \cdots, \mathrm{x}_{\mathrm{k}}^{\mathrm{U}}\right)$ are respectively the lower and upper bounds of the geometrical parameters. 
Since the crash simulation requires high computational cost, the FE modelling cannot be used directly to solve the MOD problem which requires hundreds of performance evaluations. The surrogate models such as RS models are widely in lieu of nonlinear FEA to solve the MOD problem for fast iteration. Design-Expert software, which employs the desirability approach as an optimization algorithm, was used for solving the MOD problems.

\subsection{Desirability approach:}

Generally, there are two different methods to solve the multi objective optimization problem as formulated in equation (2). The first explores all the objectives independently and searches for a set of optimal solutions known as the Pareto optimal solution. Some approaches such as genetic algorithm (GA) and particle swarm optimization (PSO) are well developed for finding the Pareto optimal solutions for multi-objective problems.

Alternatively, the second method combines all objectives into a single cost objective function in terms of a relative performance measure, for example, by using desirability approach (Geometrical average method), and results in only a single solution for the optimization problem $[10,11,34,35]$

The second method (desirability approach) was employed in this study due to its simplicity, availability in the design-expert software, relatively low computational cost and fast convergence, and because it offers flexibility in weighting and can assign different importance values for individual responses [10, 11].

Solving multi-objective optimization problems using the desirability approach consists of a technique that combines multiple responses into a dimension-less 
measure of performance, called an overall desirability function. In particular, the desirability approach indicates the transforming of each estimated response into a unit-less utility bounded by $\left(0<\mathrm{d}_{\mathrm{i}}<1\right)$, where a greater $\mathrm{d}_{\mathrm{i}}$ value indicates that response value is more desirable [49]. The shape of the desirability function can be changed for each response by assigning different weights and importance. Weights could be ranged between 0.1 and 10 while the Importance varies from the least important value of $1(+)$, to the most important value of $5(+++++)$.

The optimization function of the Design-expert V8 [49] software searches for a combination of factor levels that simultaneously satisfy the desired requirements from each of the responses and factors. The optimization process involves combining the goals into an overall desirability function (D). The numerical optimization feature in the Design expert V8 software package searches for one or more points in the factors domain that will maximize the desirability function (D). The optimal solution obtained by applying the desirability method is the one with a high desirability magnitude.

\subsection{Design optimization results:}

In this paper, the RS models presented in section 3.1 were used to perform the MOD design of the sandwich tube. The multi-objectives design is aimed at achieving the maximum SEA and to minimize the value of the collapse load (F) as stated in equation (2). The geometric parameters $D_{0}, t_{0}, D_{i}$, and $t_{i}$ of the sandwich tube were set to vary in order to seek the optimal configuration of the sandwich tube.

Using the desirability approach, two different optimization criteria were considered. 
In the first criterion, equal importance was assigned for both objectives but a more emphasis was given to the SEA objective by specifying the maximum weight for it as it is more important in the energy absorbing components to obtain a higher SEA. While in the second criterion, further emphasis was given to SEA objective by specifying the maximum weight and importance for it and less emphasis was given to F objective through assigning the minimum importance for it.

Table 6 and Table 7 show the responses and the variable constraints of the optimization criteria.

The desirability objective function vs design variables Do and Di for both optimization criteria are shown in Figure 20 and Figure 21 respectively. It can be seen that the overall desirability increases as the outer tube diameter increases and the inner tube diameter decreases.

The optimum tube configurations and the corresponding ideal optimal values of the two single objective functions SEA and F predicted by the RS models are presented in Table 8 . It can be seen that the optimal solutions are nearly identical and the only minor difference is in the value of ti. For both optimal solutions, the greatest desirability is offered by the tubes with $\mathrm{Do}=130 \mathrm{~mm}$, to $=1.5 \mathrm{~mm}$ and $\mathrm{Di}=80 \mathrm{~mm}$. Therefore, a multi-objective optimization design configuration can be obtained if a tube with a minimum diameter of the inner layer and a maximum foam thickness is used.

Numerical simulations were performed using the optimized conditions in order to validate the optimized results. Table 9 presents comparisons between the numerical results obtained by ANSYS and their corresponding predicted results obtained by the RS models. It can be seen that the numerical results $(\mathrm{FE})$ are in good agreement with the predicted results (RSM). This indicates that the optimized results are valid. 
As the optimal configurations are almost identical, their force and energy responses are also very similar. Figure 22 shows the force and energy responses along with the various stages of deformation for the optimal configuration with $D o=130 \mathrm{~mm}$, to $=1.5$ $\mathrm{mm}, \mathrm{Di}=80 \mathrm{~mm}$ and $\mathrm{ti}=3 \mathrm{~mm}$.

For the purposes of comparison and validation of optimization results obtained by desirability approach, the Genetic Algorithm (GA) based multi-objective optimization solver of Matlab is used to solve the multi-objective problem as defined in equation (2). As mentioned before, the Genetic Algorithm (GA) generates a set of optimal solutions, in contrast to the single solution of the desirability approach, known as Pareto frontier. In MATLAB, the established response surface models of F and SEA placed in one M-file. The solutions for Multi-objective optimization problem using GA are given in Figure 23. It is clear from this figure that the SEA and F strongly conflict with each other where any improvement in one of them must sacrifice the second. It should be noted that minimizing the term -SEA in the Pareto frontier means maximizing SEA. The Figure 23 also shows the optimization results obtained from desirability approach. It can be seen that the optimization results using the desirability approach are in very good agreement with those corresponding to GA and signify specific points in the Pareto frontiers. It is interesting to note that the optimal solutions obtained from desirability approach have the highest values of both objectives between all Pareto frontier points.

\section{Conclusion}

Based on existing experimental study, a finite element model has been developed to investigate the energy absorption through the lateral collapse of the sandwich circular tube. Factorial analysis was performed by employing the D-optimal design method of the design of experiment (DOE). The geometrical factors were selected as 
design variables. The specific energy absorption (SEA) and collapse load (F) were formulated as design responses. Moreover, the multi objective optimization design (MOD) was carried out in order to establish the optimal configuration of sandwich tubes used as energy absorbing components. As a practical implication, the main outcomes of the factorial analysis and optimization study for design purposes are drawn as follows.

The SEA of sandwich tube under lateral loading increased with increasing the thickness of the foam core.

The collapse load (F) was also found to be higher in tubes with thicker foam cores.

From MOD studies, it was found that the sandwich tubes with greater foam thicknesses and smaller inner layers are preferable for use in crashworthiness enhancement components.

\section{Acknowledgements}

The scholarship funding provided for the first author by the University of Aleppo is gratefully acknowledged. 


\section{References}

[1] DeRuntz Jr, J.A.and Hodge Jr, P., (1963), "Crushing of a tube between rigid plates", Journal of Applied Mechanics, Vol.30 pp. 391.

[2] Reid, S.and Reddy, T.Y., (1978), "Effect of strain hardening on the lateral compression of tubes between rigid plates", Int.J.Solids Structures, Vol.14 (3), pp. 213-225.

[3] Reddy, T.Y.and Reid, S., (1980), "Phenomena associated with the crushing of metal tubes between rigid plates", Int.J.Solids Structures, Vol.16 (6), pp. 545-562.

[4] Gupta, N., Sekhon, G.and Gupta, P., (2005), "Study of lateral compression of round metallic tubes", Thin-walled structures, Vol.43 (6), pp. 895-922.

[5] Morris, E., Olabi, A.and Hashmi, M., (2007), "Lateral crushing of circular and non-circular tube systems under quasi-static conditions", Journal of Materials Processing Tech., Vol.191 (1-3), pp. 132-135.

[6] Morris, E., Olabi, A.and Hashmi, M., (2006), "Analysis of nested tube type energy absorbers with different indenters and exterior constraints", Thin-Walled Structures, Vol.44 (8), pp. 872-885.

[7] Olabi, A., et al., (2008), "Optimised design of nested oblong tube energy absorbers under lateral impact loading", Int.J.Impact Eng., Vol.35 (1), pp. 10-26.

[8] Olabi, A., et al., (2008), "Optimised design of nested circular tube energy absorbers under lateral impact loading", Int.J.Mech.Sci., Vol.50 (1), pp. 104-116. 
[9] Baroutaji, A. and Olabi, A.G., (2012), "Analysis of the Effect of the Elliptical Ratio in Tubular Energy Absorbers Under Quasi-Static Conditions." In Materials with Complex Behaviour II, pp. 323-336. Springer Berlin Heidelberg.

[10] Baroutaji, A., et al., (2014), "Quasi-static response and multi-objective crashworthiness optimization of oblong tube under lateral loading", Thin-Walled Structures, Vol.82, pp. 262-277.

[11] Baroutaji, A., et al., (2015), "Crush analysis and multi-objective optimization design for circular tube under quasi-static lateral loading”, Thin-Walled Structures, Vol.86, pp. 121-131.

[12] Fan, Z., et al. (2013). "Dynamic lateral crushing of empty and sandwich tubes". International Journal of Impact Engineering, Vol.53, pp. 3-16.

[13] Børvik, T., et al., (2003), "Empty and foam-filled circular aluminium tubes subjected to axial and oblique quasistatic loading", International journal of crashworthiness, Vol.8 (5), pp. 481-494.

[14] Kavi, H., Toksoy, A.K.and Guden, M., (2006), "Predicting energy absorption in a foam-filled thin-walled aluminum tube based on experimentally determined strengthening coefficient", Mater Des, Vol.27 (4), pp. 263-269.

[15] Toksoy, A.and Güden, M., (2005), "The strengthening effect of polystyrene foam filling in aluminum thin-walled cylindrical tubes", Thin-walled structures, Vol.43 (2), pp. 333-350.

[16] Yan, W., et al., (2007), "Crushing simulation of foam-filled aluminium tubes", Materials transactions, Vol.48 (7), pp. 1901-1906. 
[17] Hanssen, A.G., Langseth, M.and Hopperstad, O.S., (2000), "Static and dynamic crushing of square aluminium extrusions with aluminium foam filler", Int.J.Impact Eng., Vol.24 (4), pp. 347-383.

[18] Santosa, S.P., et al., (2000), "Experimental and numerical studies of foam-filled sections", Int.J.Impact Eng., Vol.24 (5), pp. 509-534.

[19] Seitzberger, M., et al., (2000), "Experimental studies on the quasi-static axial crushing of steel columns filled with aluminium foam", Int.J.Solids Structures, Vol.37 (30), pp. 4125-4147.

[20] Zarei, H.and Kröger, M., (2008), "Optimization of the foam-filled aluminum tubes for crush box application", Thin-Walled Structures, Vol.46 (2), pp. 214-221. [21] Gupta, N.and Velmurugan, R., (1999), "Axial compression of empty and foam filled composite conical shells", J.Composite Mater., Vol.33 (6), pp. 567-591. [22] Ahmad, Z.and Thambiratnam, D., (2009), "Crushing response of foam-filled conical tubes under quasi-static axial loading", Materials and Design, Vol.30 (7), pp. 2393-2403.

[23] Ahmad, Z.and Thambiratnam, D.P., (2009), "Dynamic computer simulation and energy absorption of foam-filled conical tubes under axial impact loading", Comput.Struct., Vol.87 (3), pp. 186-197.

[24] Ahmad, Z., Thambiratnam, D.and Tan, A., (2010), "Dynamic energy absorption characteristics of foam-filled conical tubes under oblique impact loading", Int.J.Impact Eng., Vol.37 (5), pp. 475-488.

[25] Mirfendereski, L., Salimi, M.and Ziaei-Rad, S., (2008), "Parametric study and numerical analysis of empty and foam-filled thin-walled tubes under static and dynamic loadings", Int.J.Mech.Sci., Vol.50 (6), pp. 1042-1057. 
[26] Reid, S.and Reddy, T., (1986), "Static and dynamic crushing of tapered sheet metal tubes of rectangular cross-section", Int.J.Mech.Sci., Vol.28 (9), pp. 623-637. [27] Chen, W. (2001), "Experimental and numerical study on bending collapse of aluminum foam-filled hat profiles", Int.J.Solids Structures, Vol.38 (44), pp. 79197944.

[28] Song, H., et al., (2005), "Partition energy absorption of axially crushed aluminum foam-filled hat sections", Int.J.Solids Structures, Vol.42 (9), pp. 25752600.

[29] Fan, Z., Shen, J.and Lu, G., (2011), "Investigation of Lateral Crushing of Sandwich Tubes", Procedia Engineering, Vol.14 pp. 442-449.

[30] Shen, J., Lu, G., Zhao, L., and Zhang, Q. (2013). Short sandwich tubes subjected to internal explosive loading. Engineering Structures, 55, 56-65.

[31] Shen, J., et al., (2014), "Lateral plastic collapse of sandwich tubes with metal foam core", International Journal of Mechanical Sciences http://dx.doi.org/10.1016/j.ijmecsci.2013.11.016i.

[32] Baroutaji, A. and Olabi, A. G., (2014), "Lateral collapse of short-length sandwich tubes compressed by different indenters and exposed to external constraints", Materialwissenschaft und Werkstofftechnik, Vol.45 (5).

[33] Hou, S., et al., (2007), "Design optimization of regular hexagonal thin-walled columns with crashworthiness criteria", Finite Elements Anal.Des., Vol.43 (6), pp. $555-565$

[34] Hou, S., et al., (2008), "Multiobjective optimization of multi-cell sections for the crashworthiness design", Int.J.Impact Eng., Vol.35 (11), pp. 1355-1367. 
[35] Hou, S., et al., (2009), "Crashworthiness design for foam filled thin-wall structures", Mater Des, Vol.30 (6), pp. 2024-2032.

[36] Liu, Y. (2008), "Crashworthiness design of multi-corner thin-walled columns", Thin-Walled Structures, Vol.46 (12), pp. 1329-1337.

[37] Liu, Y. (2008), "Optimum design of straight thin-walled box section beams for crashworthiness analysis", Finite Elements Anal.Des., Vol.44 (3), pp. 139-147.

[38] Zarei, H.and Kröger, M., (2008), "Optimum honeycomb filled crash absorber design", Mater Des, Vol.29 (1), pp. 193-204.

[39] Yin, H., et al., (2011), "Crushing analysis and multiobjective crashworthiness optimization of honeycomb-filled single and bitubular polygonal tubes", Mater Des, Vol.32 (8), pp. 4449-4460.

[40] Zarei, H.and Kröger, M., (2008), "Bending behavior of empty and foam-filled beams: Structural optimization", Int.J.Impact Eng., Vol.35 (6), pp. 521-529.

[41] Zhang, Z., Liu, S.and Tang, Z., (2009), "Design optimization of cross-sectional configuration of rib-reinforced thin-walled beam", Thin-walled structures, Vol.47 (8), pp. 868-878.

[42] Qi, C., Yang, S.and Dong, F., (2012), "Crushing analysis and multiobjective crashworthiness optimization of tapered square tubes under oblique impact loading", Thin-Walled Structures, Vol.59, pp. 103-119.

[43] Ahmad, Z. (2009), "Impact and energy absorption of empty and foam-filled conical tubes", PhD Thesis, Queensland University of Technology, 
[44] Nagel, G., (2005), "Impact and energy absorption of straight and tapered rectangular tubes", $\mathrm{PhD}$ thesis, Queensland University of Technology, Brisbane, [45] ANSYS ${ }^{\circledR}$ Academic Research, Release 14.0, Help System, ANSYS LS-DYNA User's Guide, ANSYS, Inc. 2009.

[46] Zhang, X., et al., (2014), “Axial crushing and optimal design of square tubes with graded thickness", Thin-Walled Structures, 84, 263-274.

[47] Zhang, Y., et al., (2014), "Multiobjective crashworthiness optimization of hollow and conical tubes for multiple load cases", Thin-Walled Structures, Vol.82, pp. 331-342.

[48] Yang, S. and Qi, C., (2013), "Multiobjective optimization for empty and foamfilled square columns under oblique impact loading”, International Journal of Impact Engineering, Vol.54, pp.177-191.

[49] Stat-Ease Inc. 'Design-Expert software V8 user's guide', Technical Manual, Stat Ease, Inc., Minneapolis, MN,2010.

[50] Nariman-Zadeh, N., et al., (2006), "Pareto optimization of energy absorption of square aluminium columns using multi-objective genetic algorithms", Proceedings of the Institution of Mechanical Engineers, Part B: Journal of Engineering Manufacture, Vol.220 (2), pp. 213-224.

[51] Zarei, H. R. and Kröger, M., (2006), "Multiobjective crashworthiness optimization of circular aluminum tubes", Thin-walled structures, Vol.44 (3), pp. 301-308. 
Figure 1: FE model of sandwich tube.

Figure 2: Velocity-time history for the moving rigid body used in the quasi static simulation [44]

Figure 3: Comparison of kinetic and internal energy for FE model of sandwich tube

Figure 4: Load -deflection response at three different velocities

Figure 5: comparison of FE \& experimental results for sandwich tube system under quasi-static loading.

Figure 6: collapse stages of sandwich tube as predicted by FE simulation

Figure 7: Energy absorbed by each component of sandwich tube.

Figure 8: Collapse sequence of the sandwich tube under quasi-static loading.

Figure 9: Flow chart showing the steps of creating the RS models

Figure 10: a: Sandwich tube geometry with design variables, b: typical forcedisplacement responses of sandwich tube with design responses.

Figure 11: Scatter diagram of SEA.

Figure 12: Scatter diagram of $F$.

Figure 13: Interaction effect of $\mathrm{D}_{\mathrm{o}}$ and $\mathrm{t}_{\mathrm{o}}$ on SEA.

Figure 14: Interaction effect of $\mathrm{D}_{\mathrm{o}}$ and $\mathrm{t}_{\mathrm{i}}$ on SEA.

Figure 15: Interaction effect of $D_{i}$ and $t_{o}$ on SEA.

Figure 16: Variation of SEA with $t_{i}$ and $D_{o}$.

Figure 17: Partition energy dissipation for each sandwich tube

Figure 18: Variation of $F$ with $t_{i}$ and $D_{0}$. 
Figure 19: Variation of F with Di and to

Figure 20: Surface of desirability objective function (D) vs. design variables (criteria 1)

Figure 21: Surface of desirability objective function (D) vs. design variables (criteria 2)

Figure 22: Responses and deformation history of the optimal configuration

Figure 23: Comparison of optimization results using different solution techniques. 
Table 1: Component material properties of the sandwich tubes [30].

Table 2: Independent variables and experimental design levels used.

Table 3: The design matrix

Table 4: Analysis of variance (ANOVA) table for SEA - Quadratic model.

Table 5: Analysis of variance (ANOVA) table for F - Quadratic model.

Table 6: Optimization criterion 1.

Table 7: Optimization criterion 2.

Table 8: Optimal solutions as obtained by Design-Expert

Table 9: Confirmation experiments of the optimal solutions. 
Figure 1: FE model of sandwich tube.

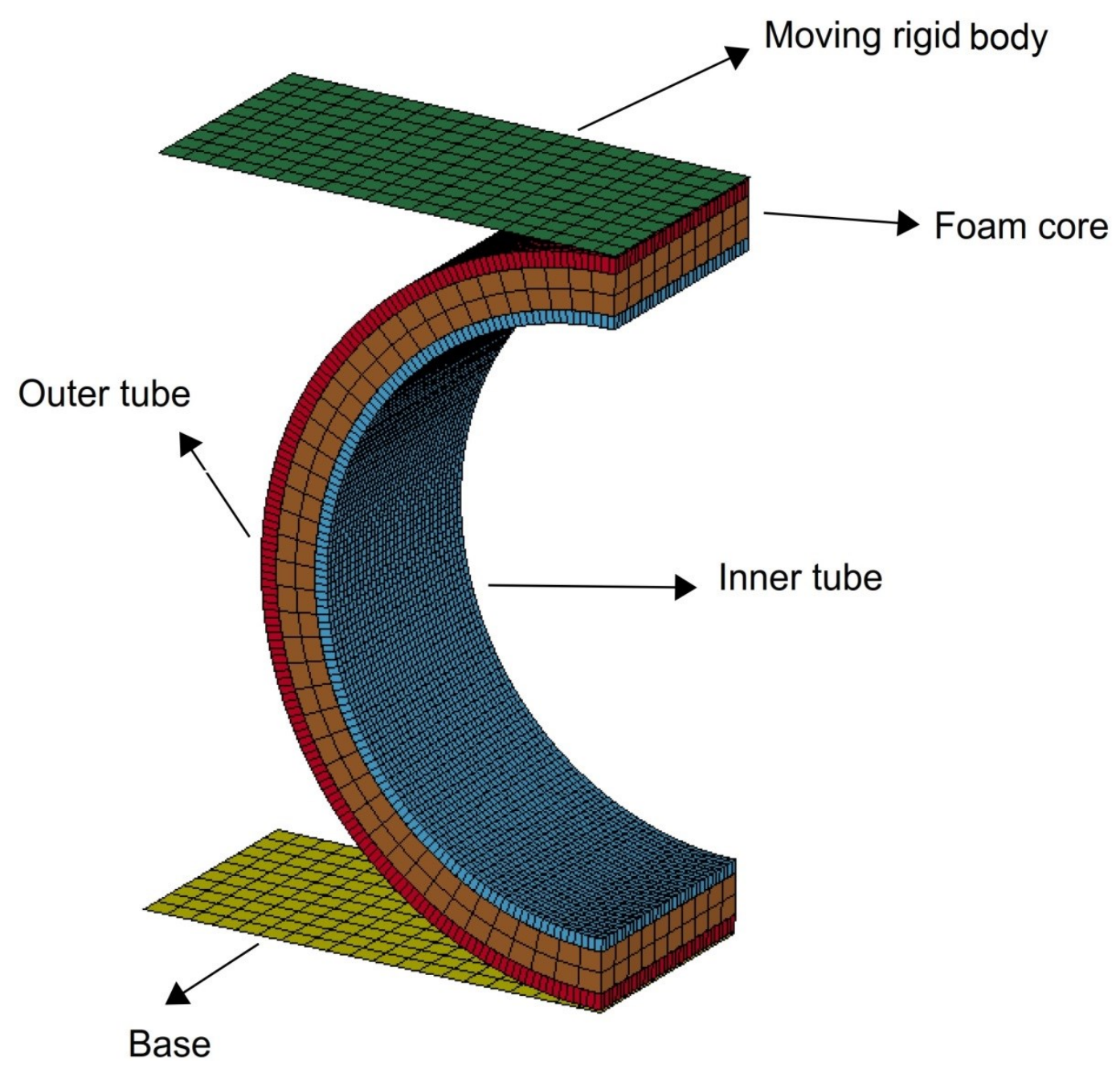


Figure 2: Velocity-time history for the moving rigid body used in the quasi static simulation [44]

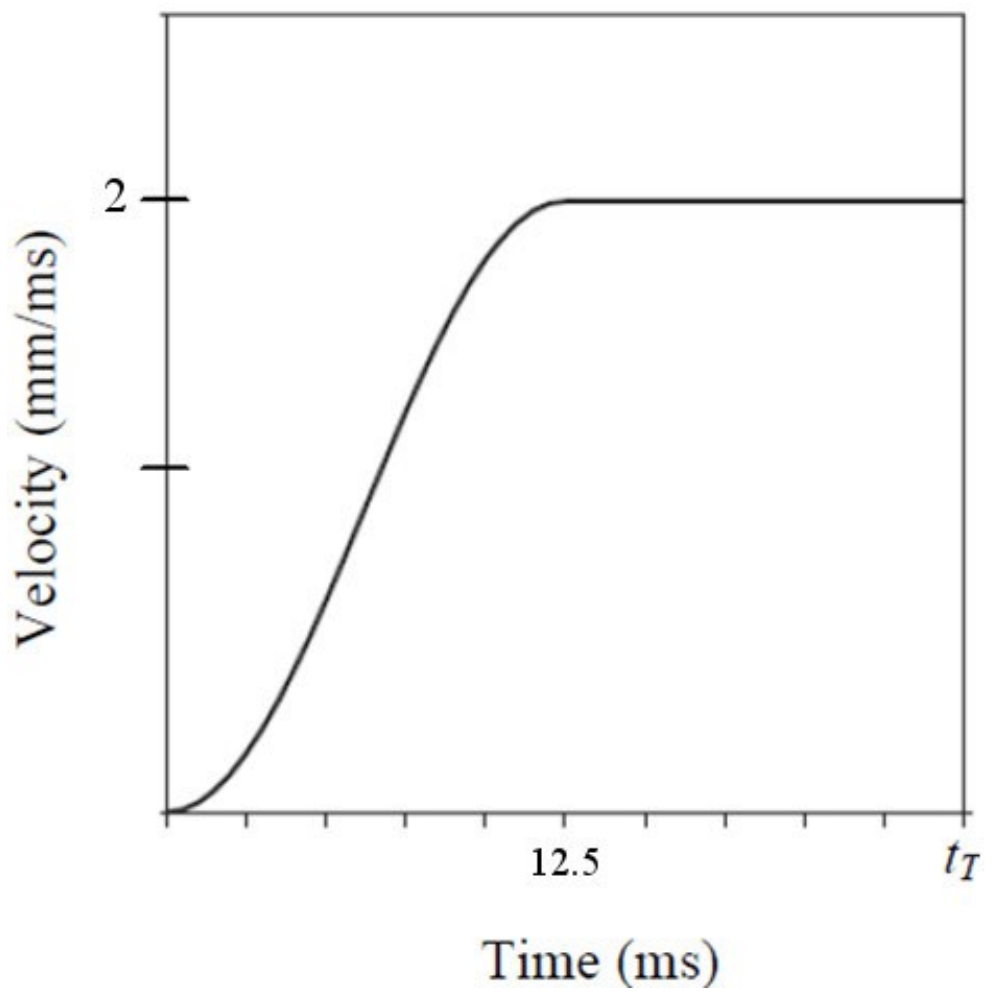


Figure 3: Comparison of kinetic and internal energy for FE model of sandwich tube

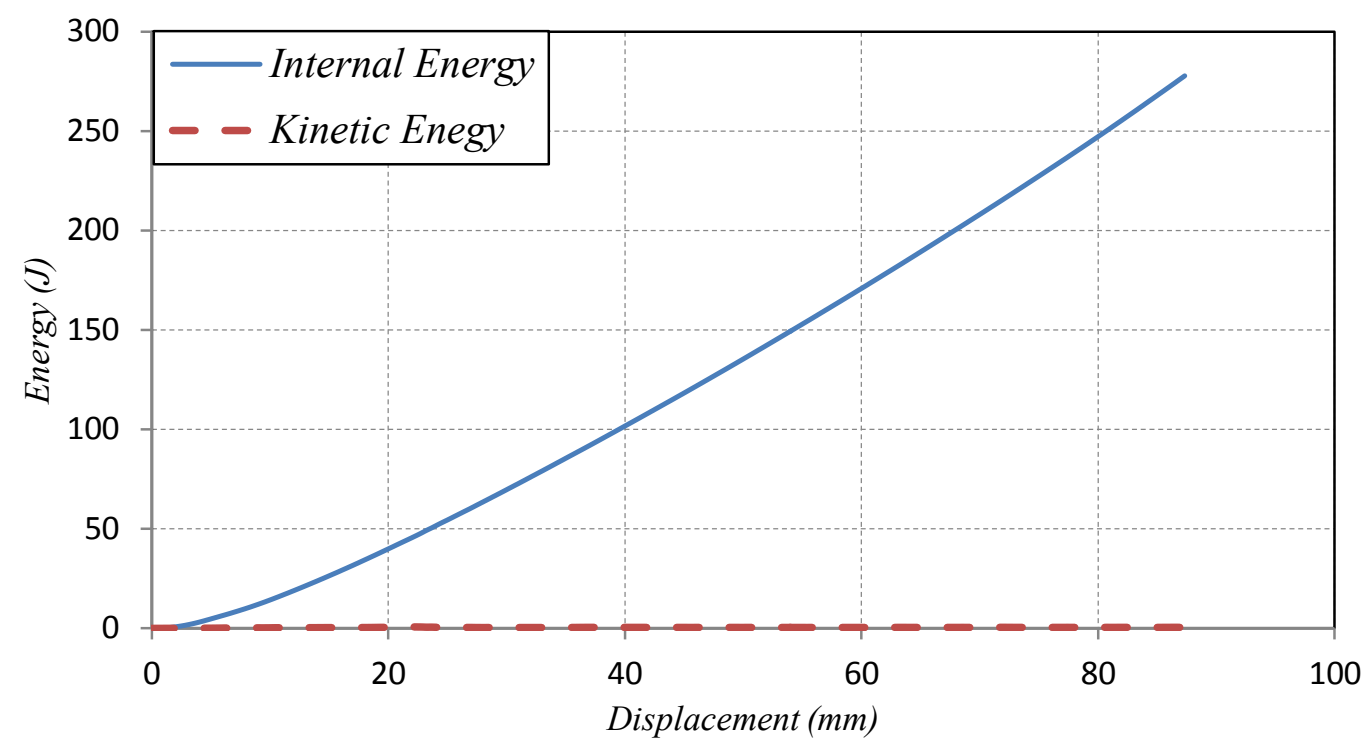


Figure 4: Load-deflection response at three different velocities

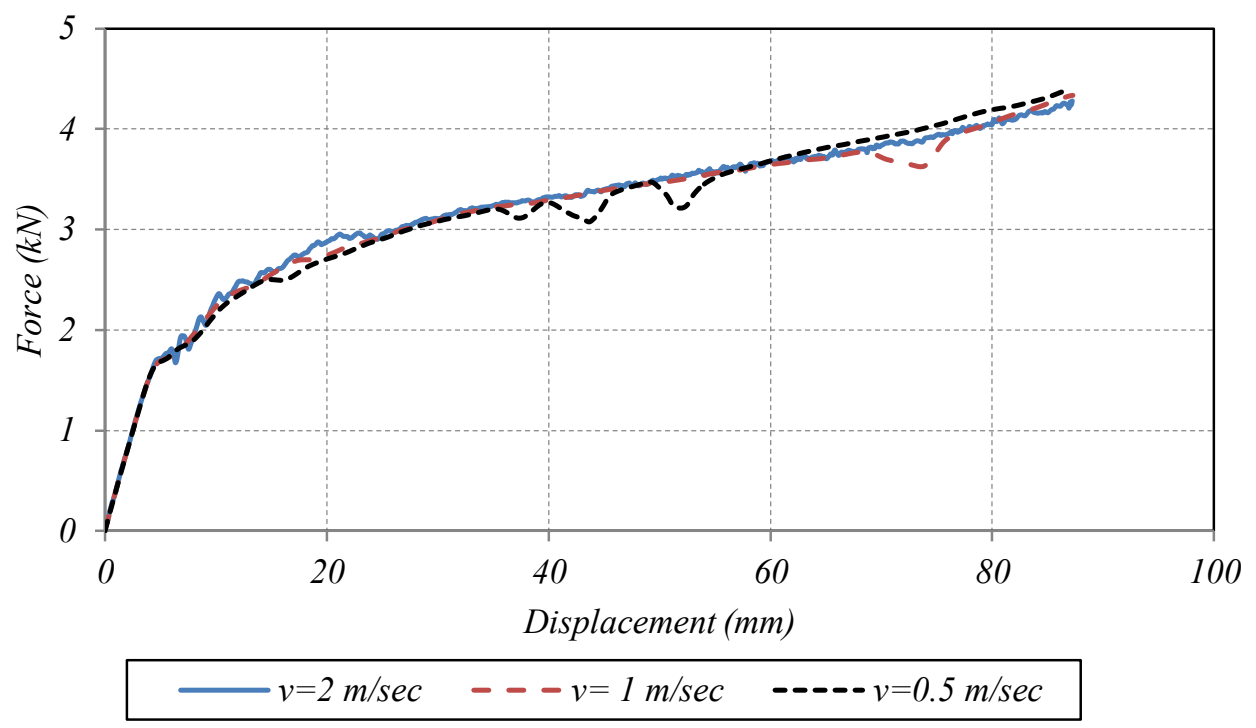


Figure 5: comparison of FE \& experimental results for sandwich tube system under quasi-static loading.

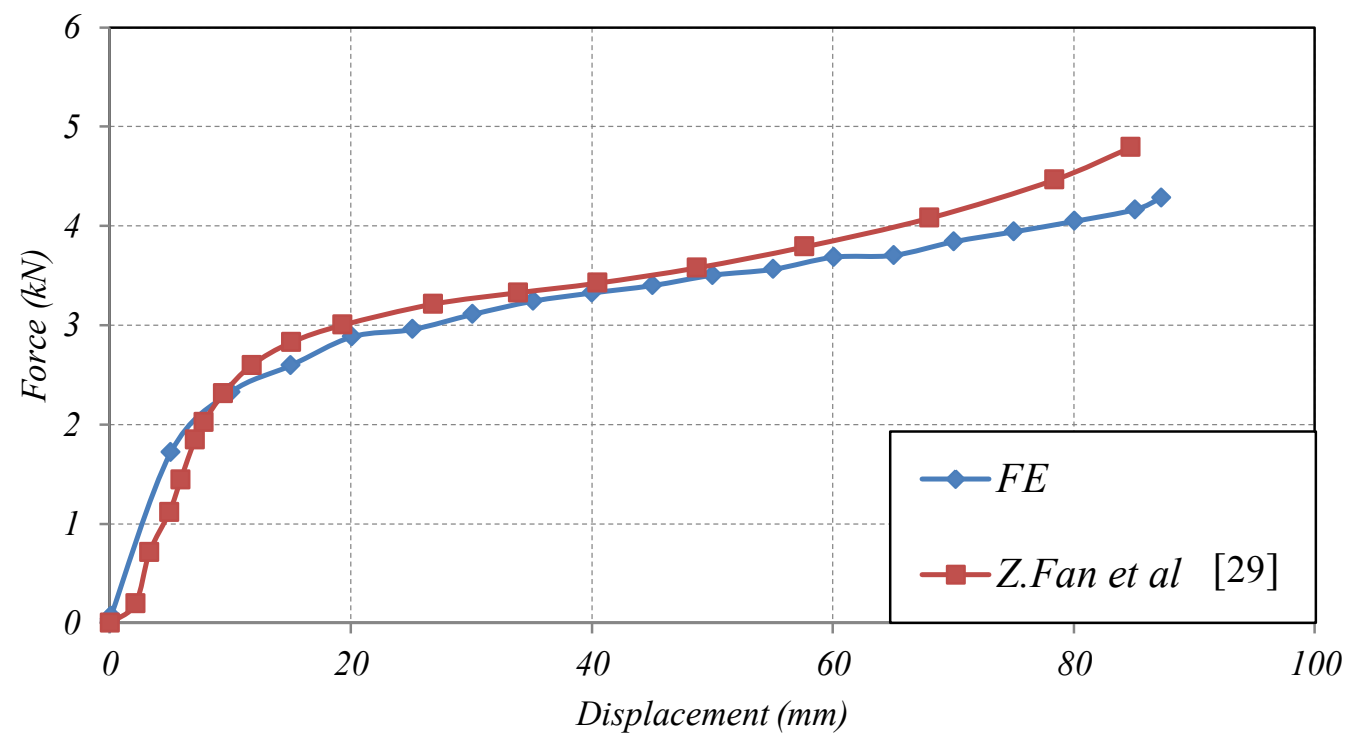


Figure 6: collapse stages of sandwich tube as predicted by FE simulation

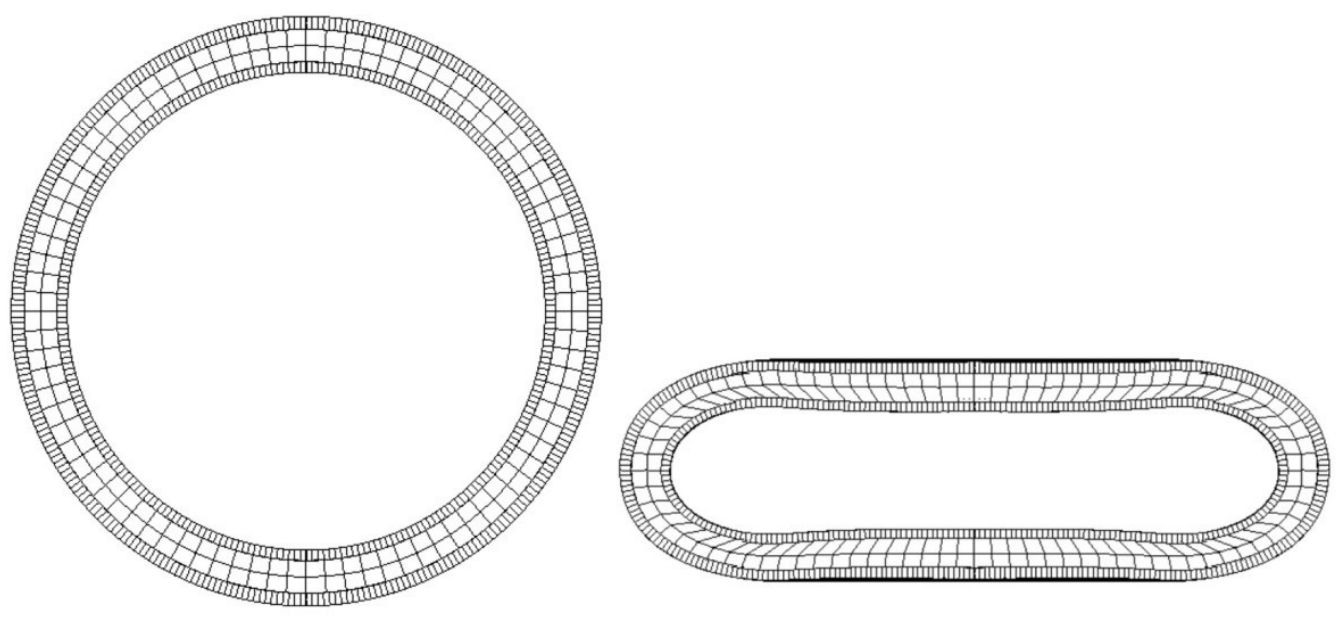


Figure 7: Energy absorbed by each component of sandwich tube.

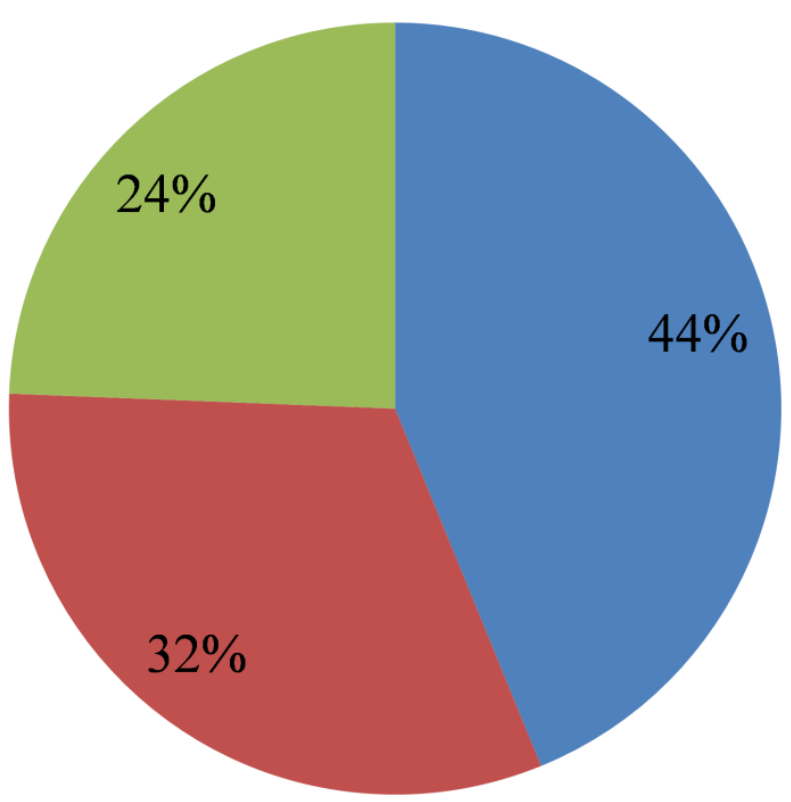

Foam $\quad$ Outer $\square$ Inner 
Figure 8: Collapse sequence of the sandwich tube under quasi-static loading.
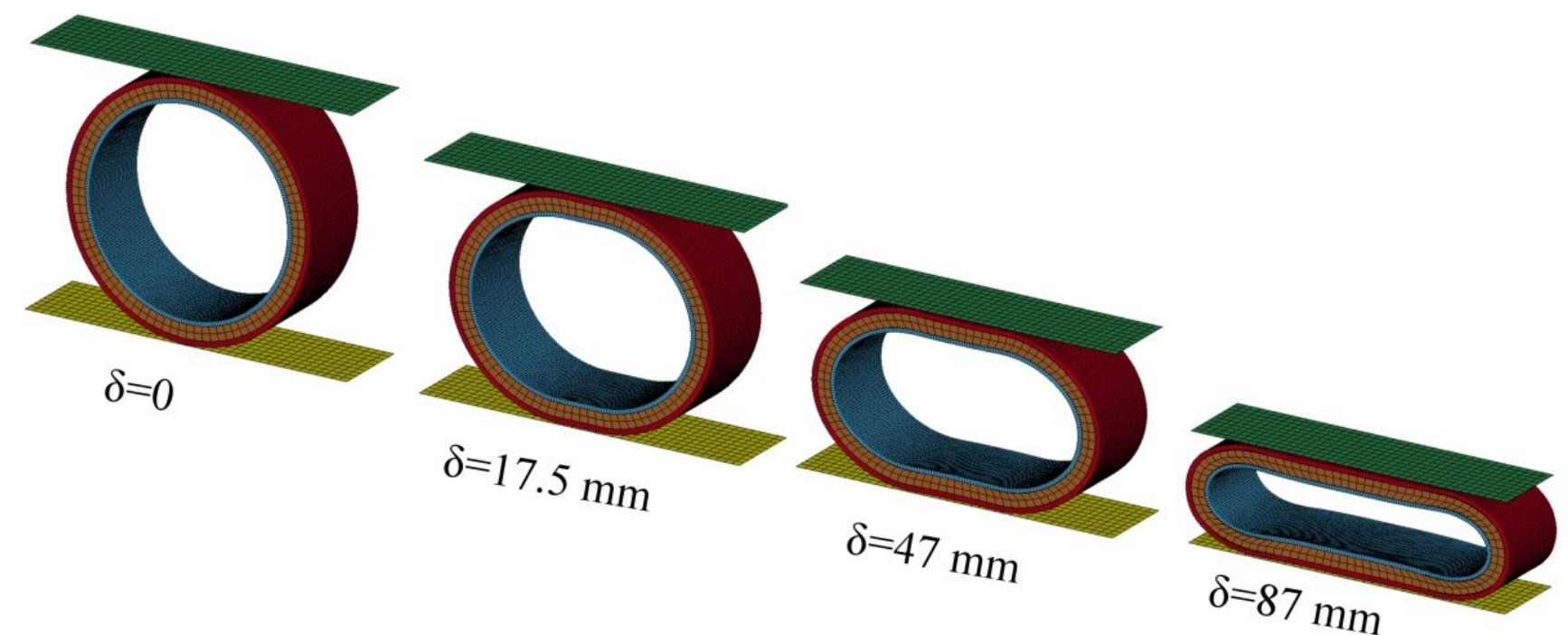
Figure 9: Flow chart showing the steps of creating the RS models

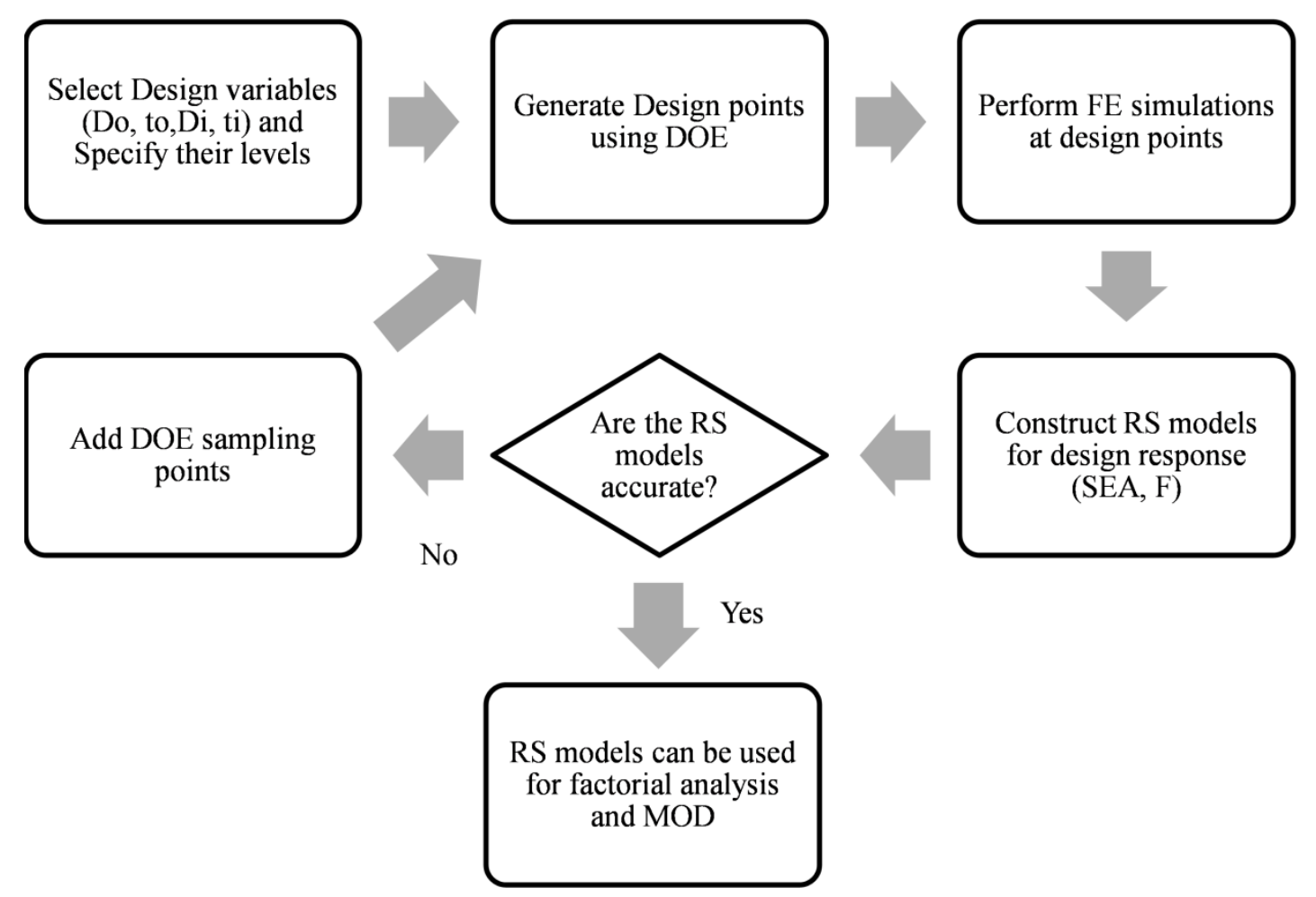


Figure 10: a: Sandwich tube geometry with design variables, b: typical forcedisplacement responses of sandwich tube with design responses.

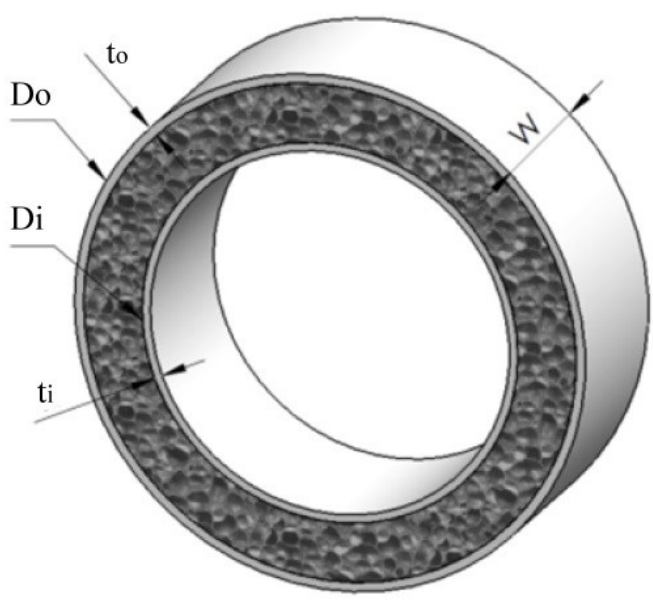

(a)

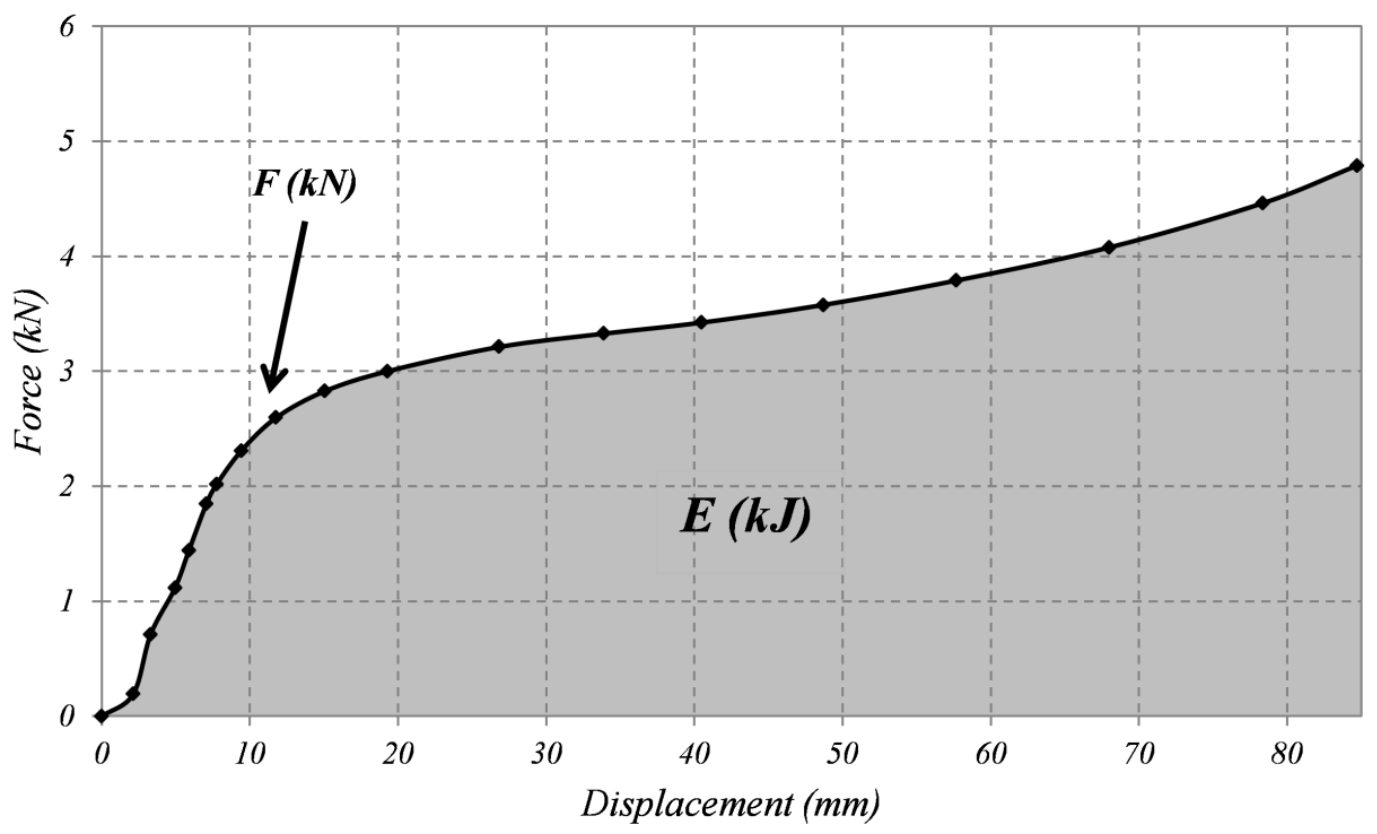

(b) 
Figure 11: Scatter diagram of SEA.

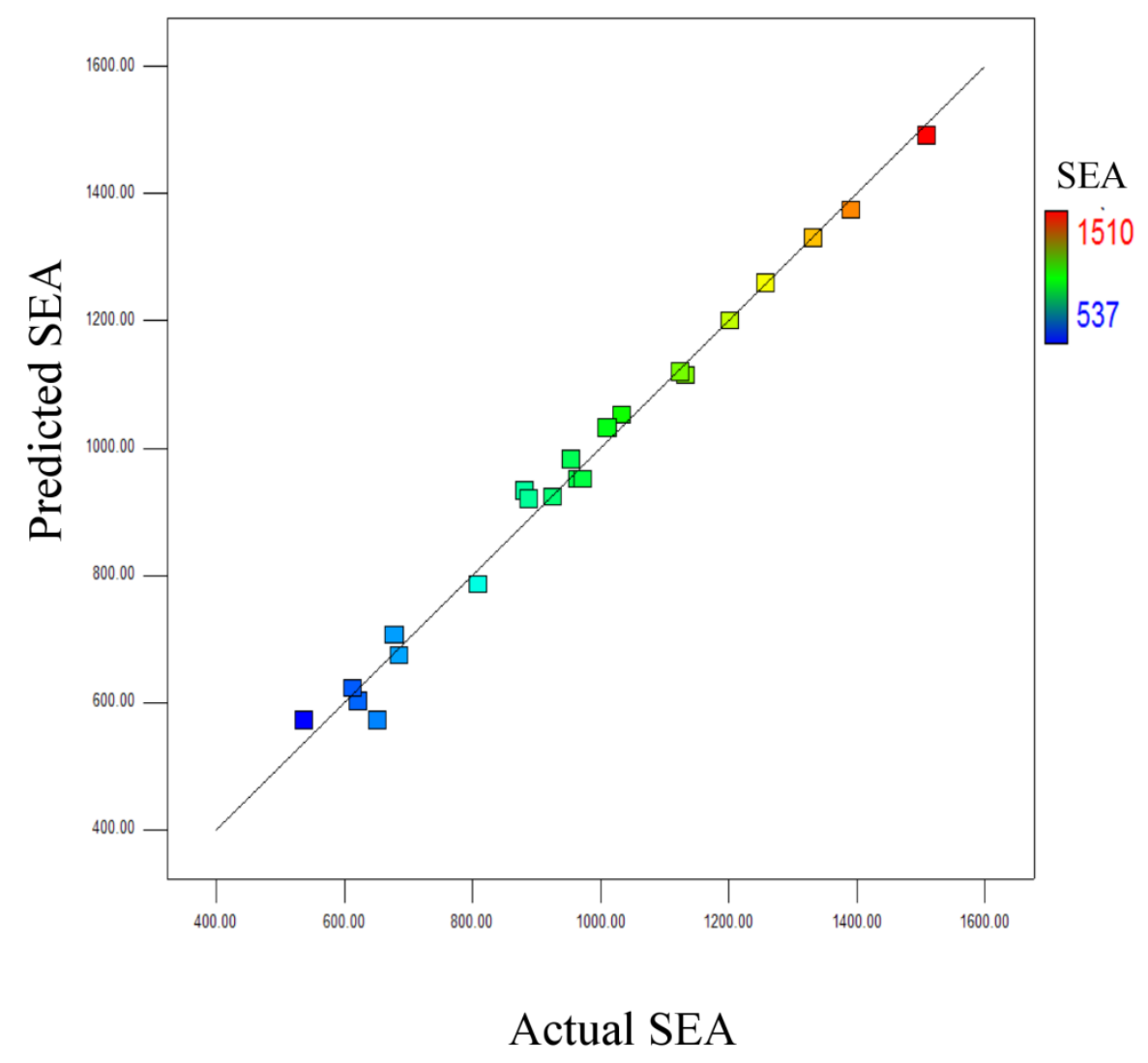


Figure 12: Scatter diagram of F.

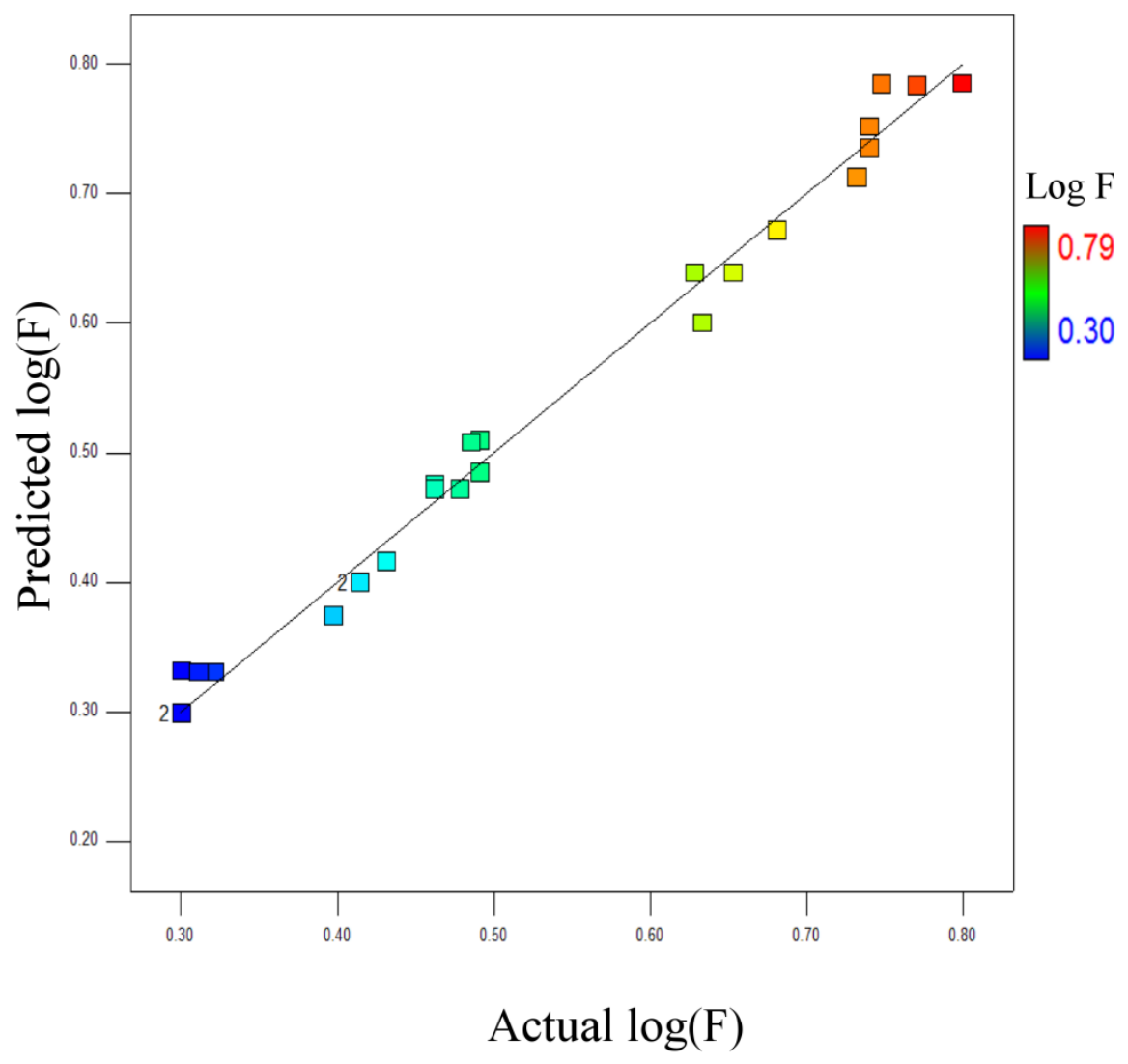


Figure 13: Interaction effect of $D_{o}$ and $t_{o}$ on SEA.

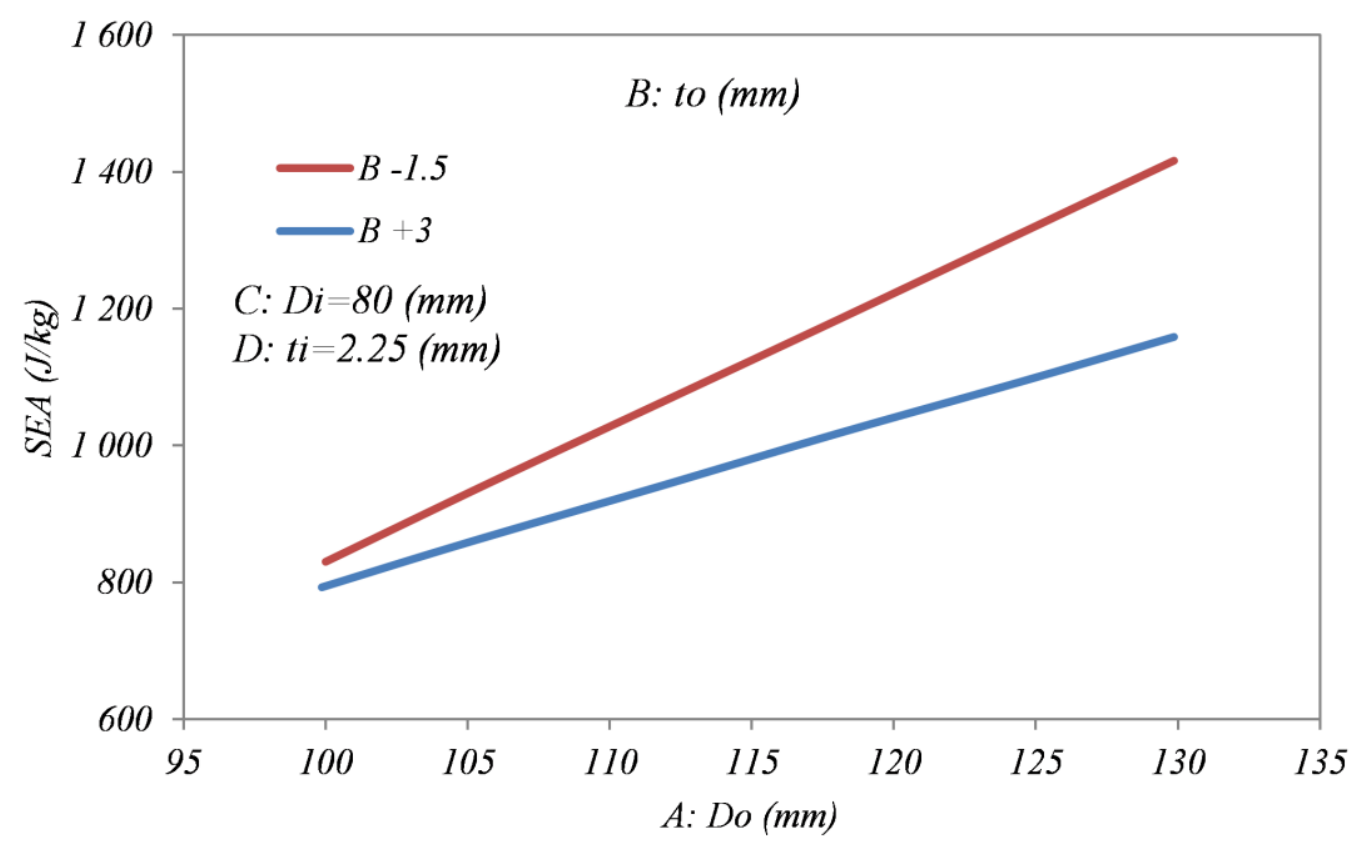


Figure 14: Interaction effect of $\mathrm{D}_{\mathrm{o}}$ and $\mathrm{t}_{\mathrm{i}}$ on SEA.

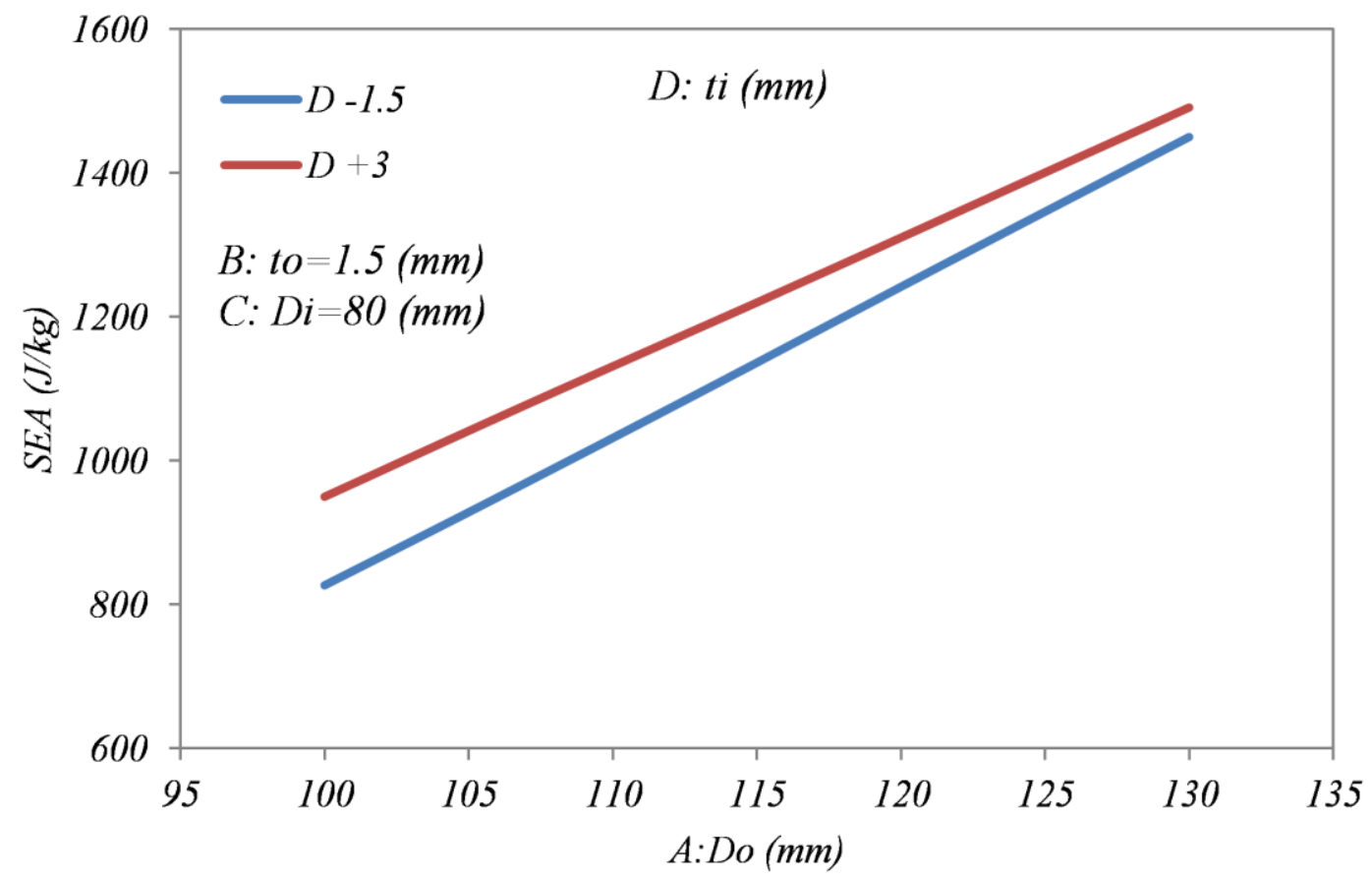


Figure 15: Interaction effect of $D_{i}$ and $t_{o}$ on SEA.

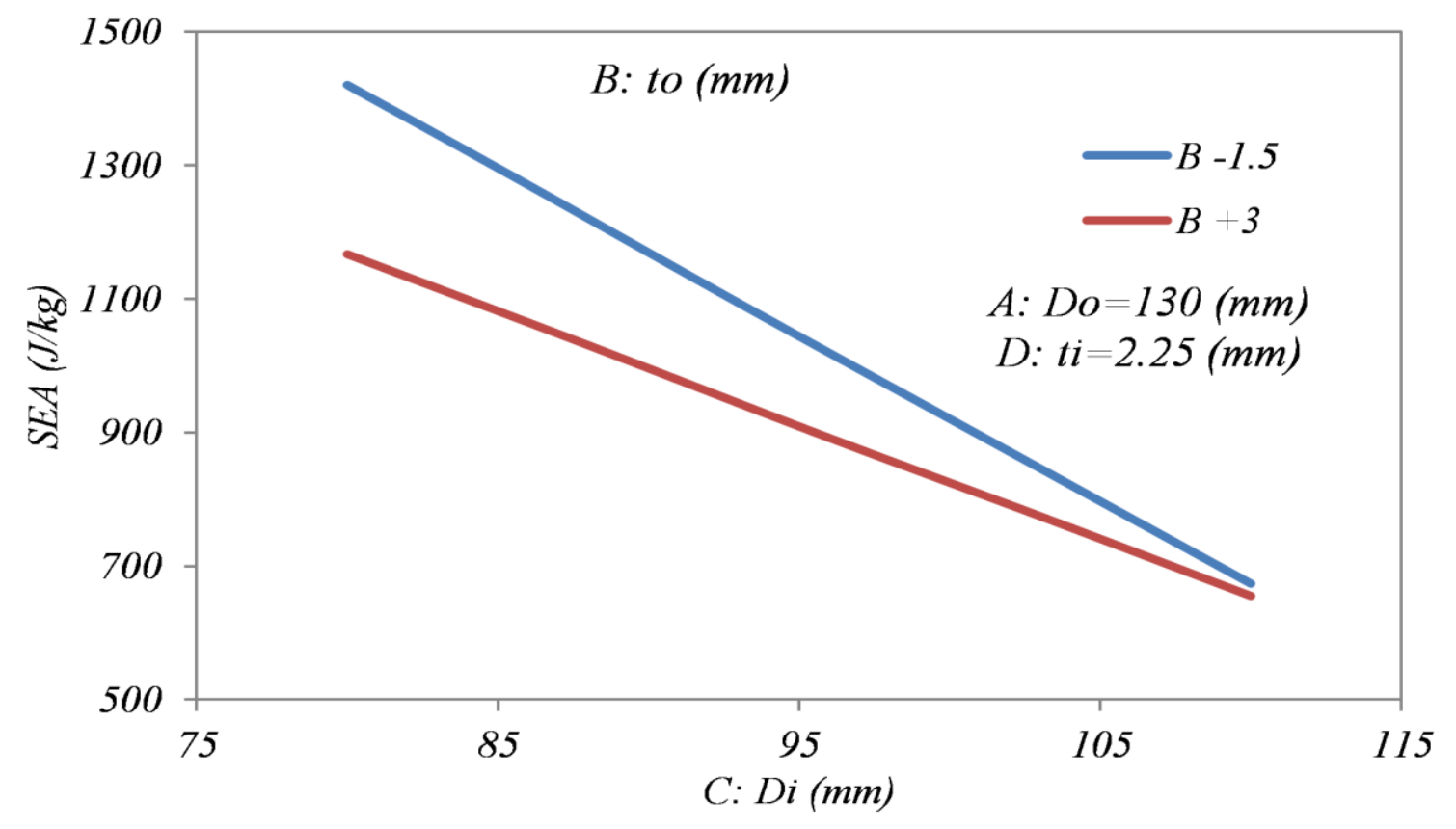


Figure 16: Variation of SEA with $t_{i}$ and $D_{0}$.

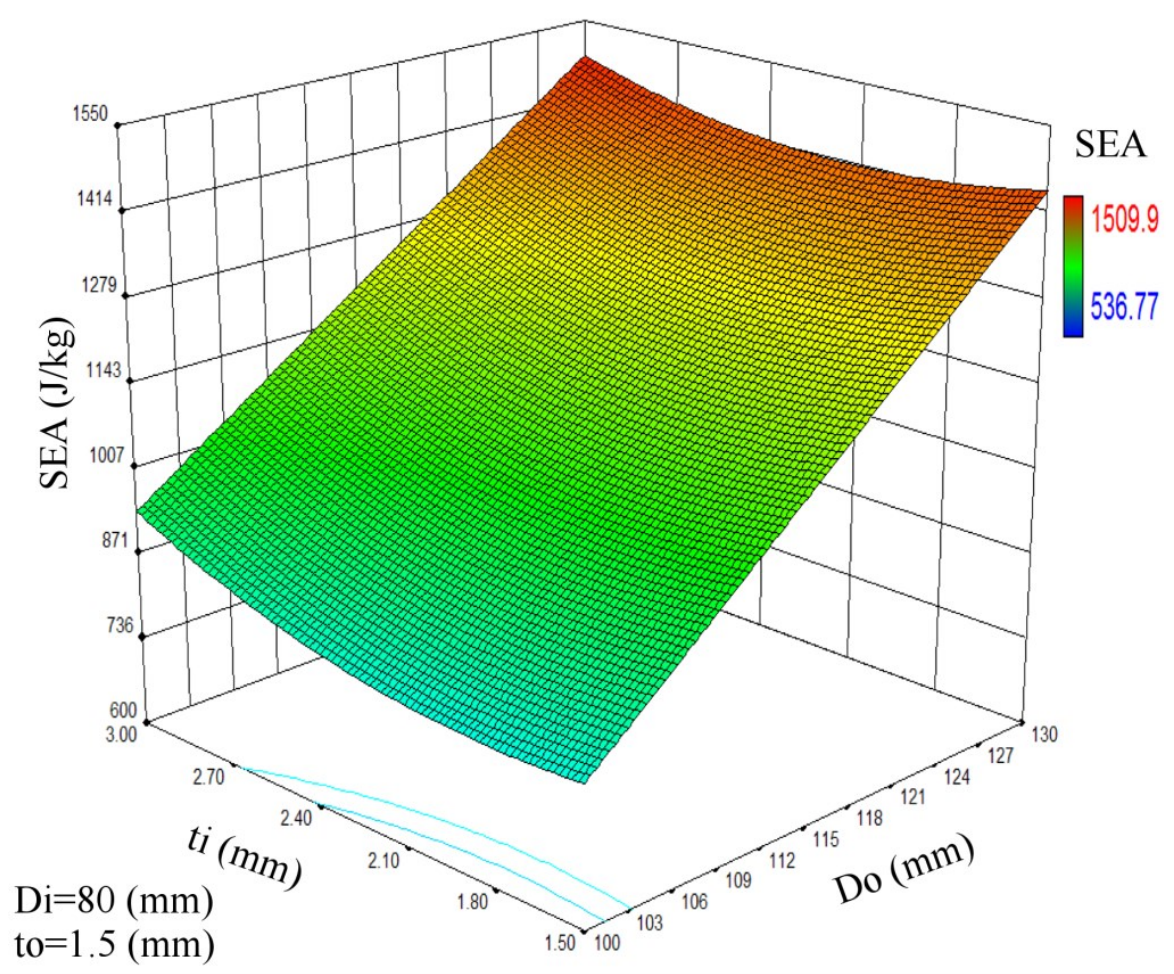


Figure 17: Partition energy dissipation for each sandwich tube

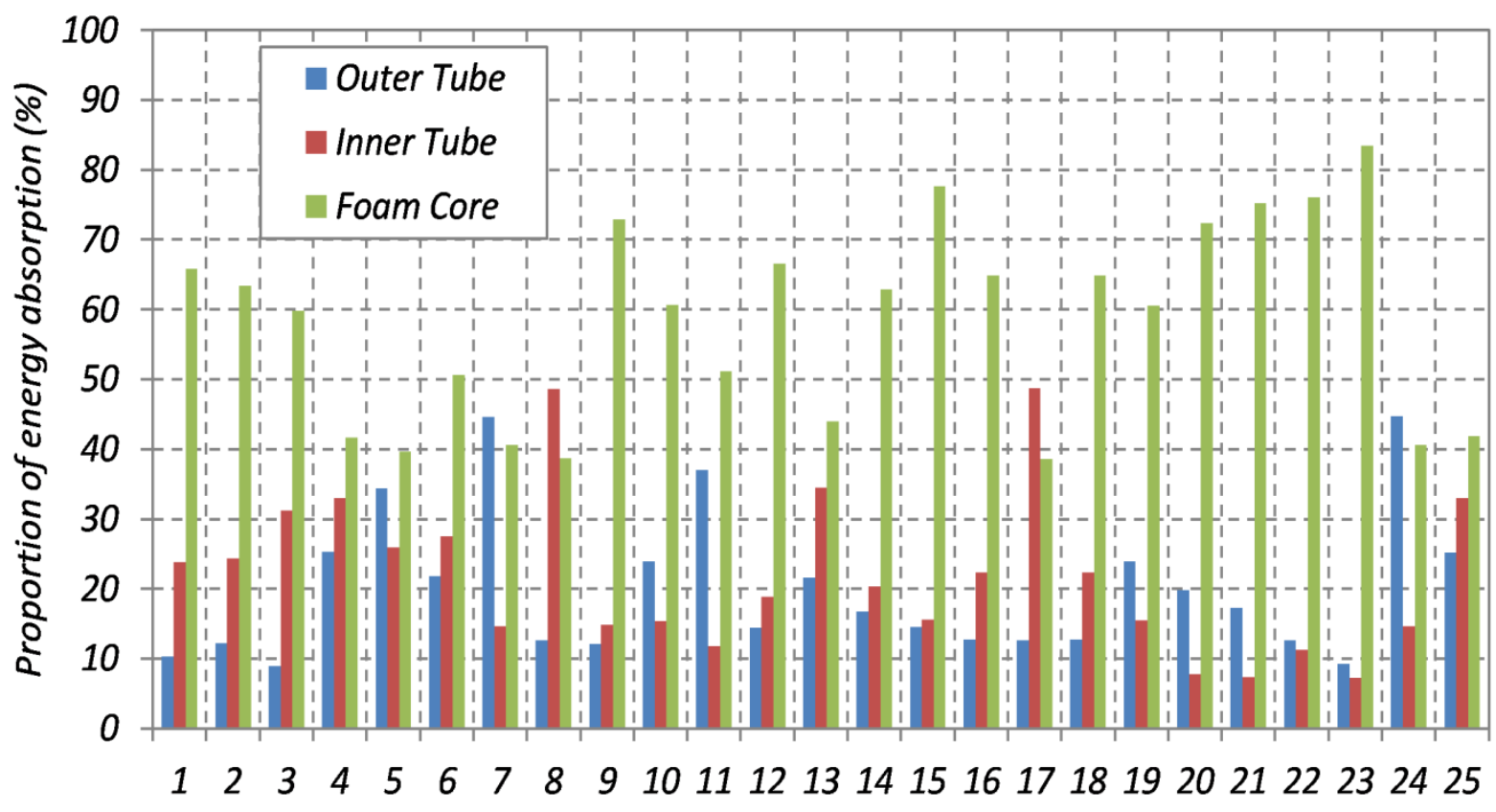


Figure 18: Variation of $F$ with $t_{i}$ and $D_{0}$.

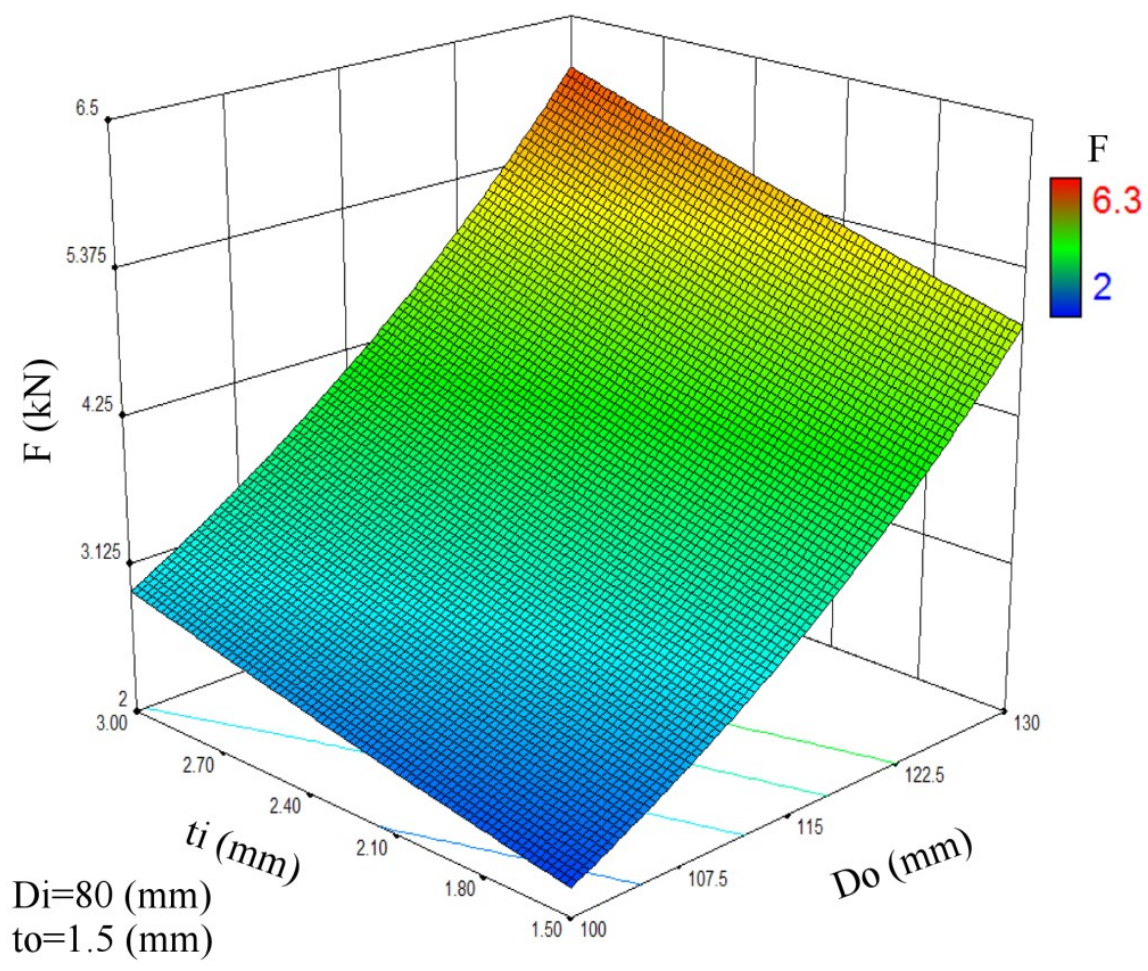


Figure 19: Variation of F with Di and to

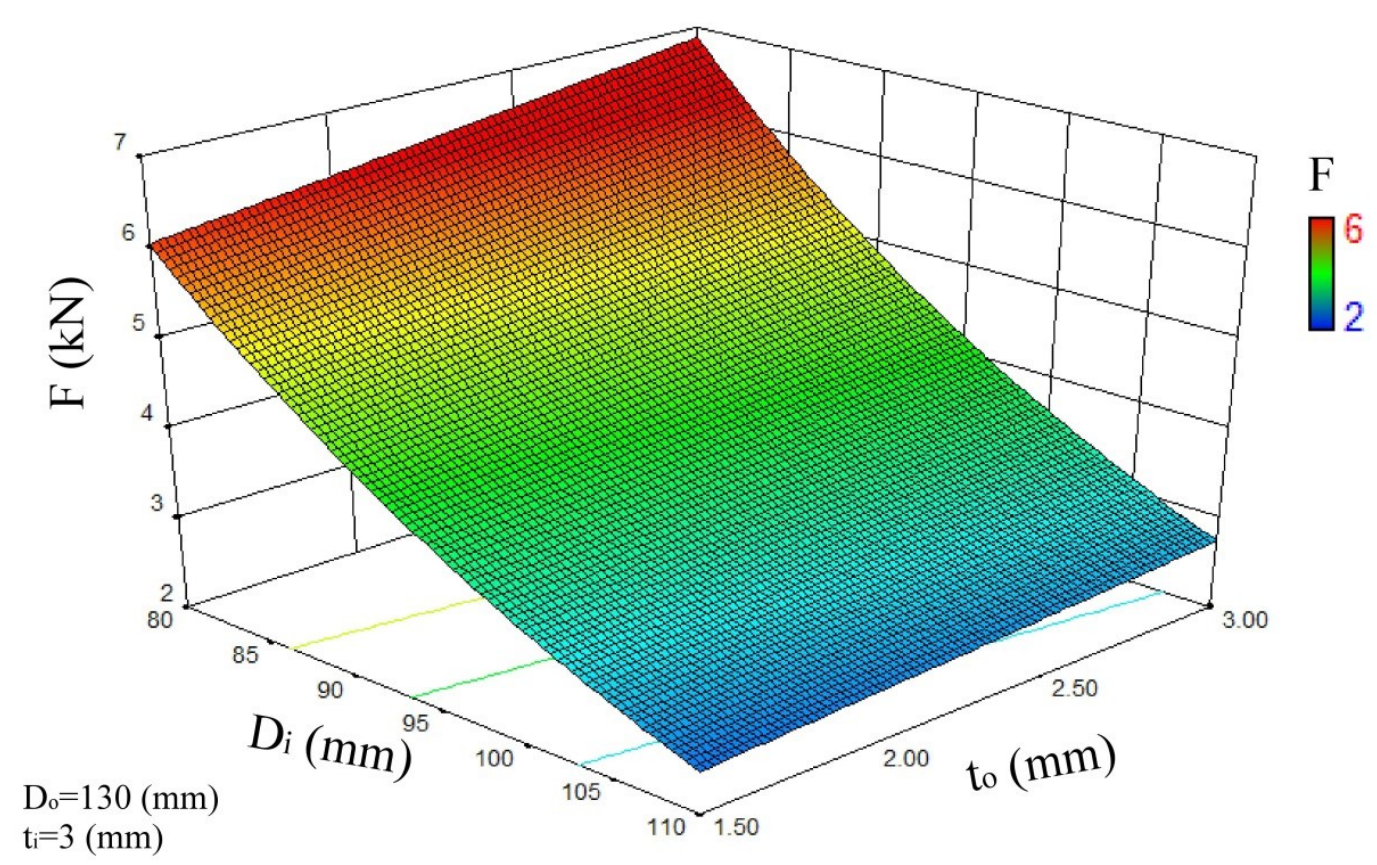


Figure 20: Surface of desirability objective function (D) vs. design variables (criteria 1)

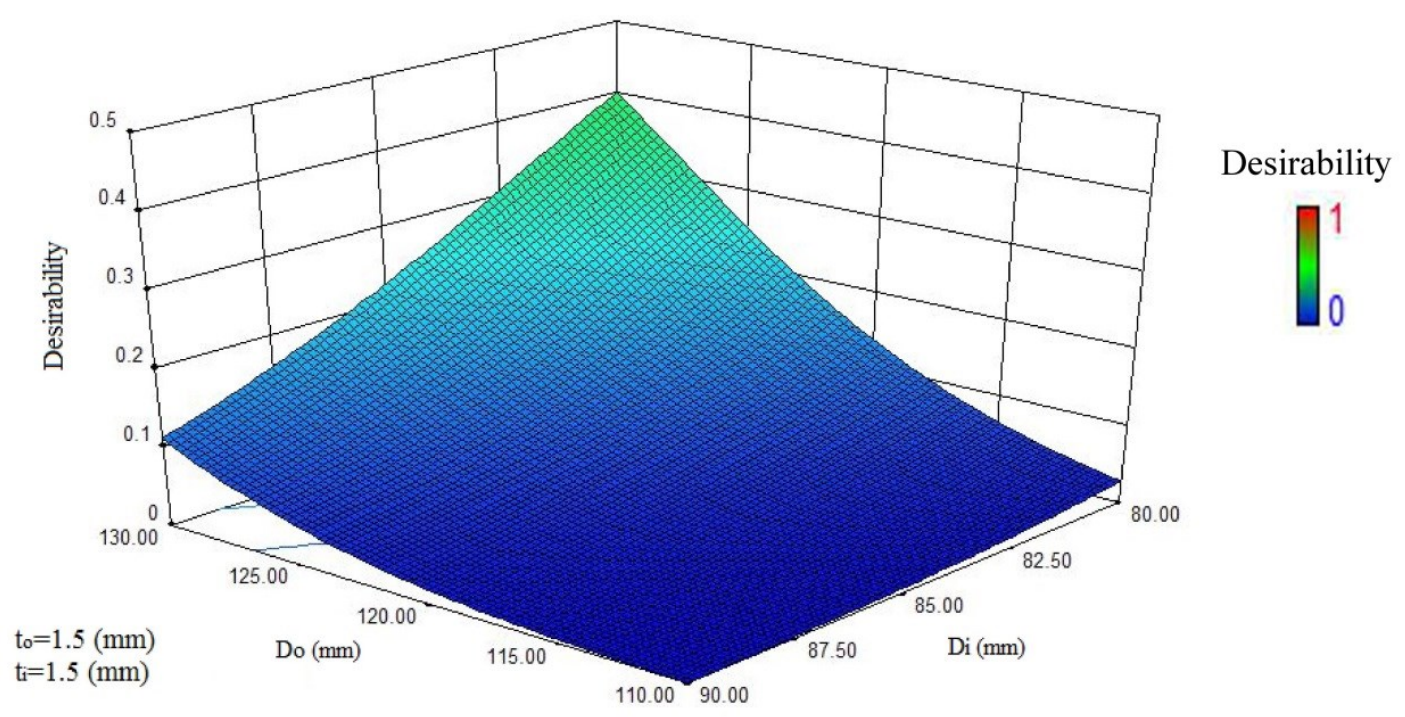


Figure 21: Surface of desirability objective function (D) vs. design variables (criteria 2)

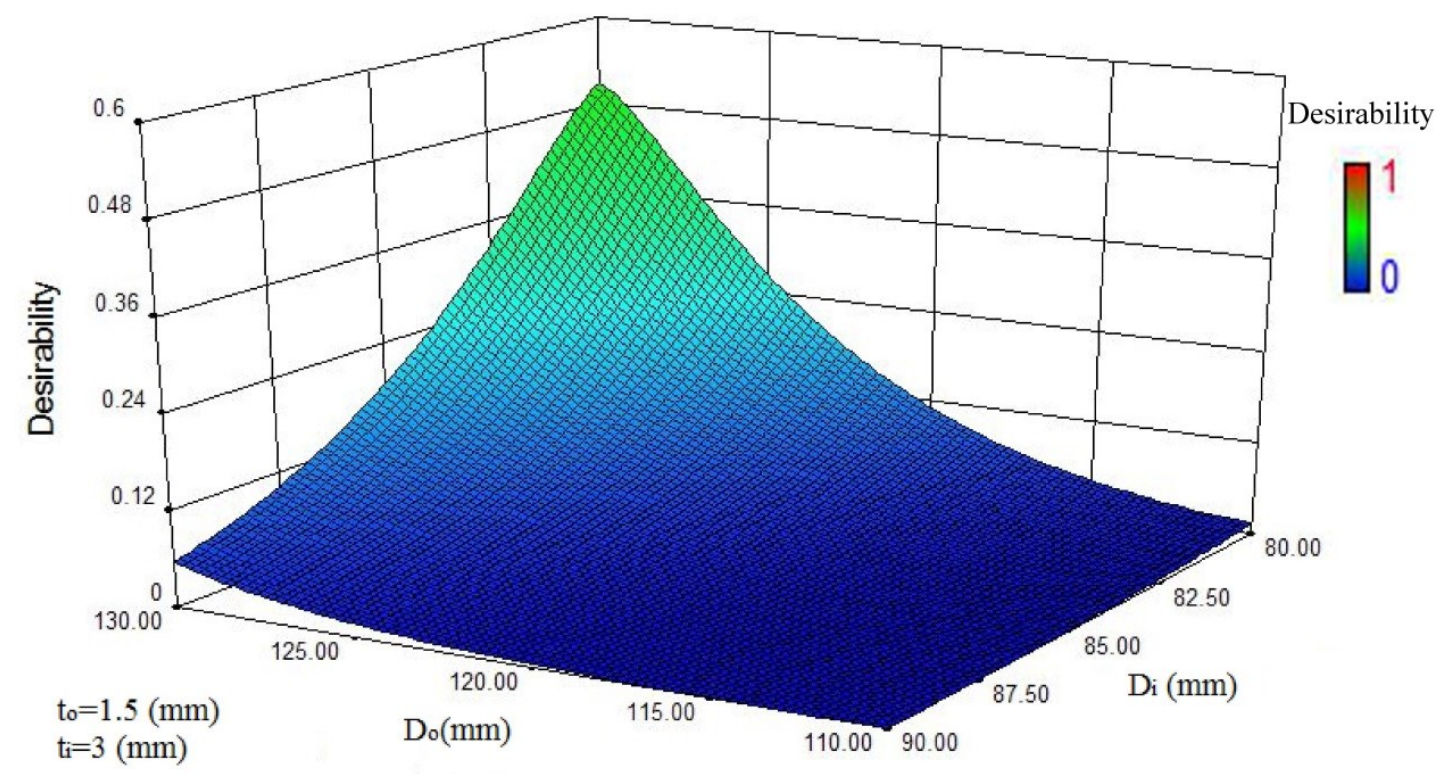


Figure 22: Responses and deformation history of the optimal configuration
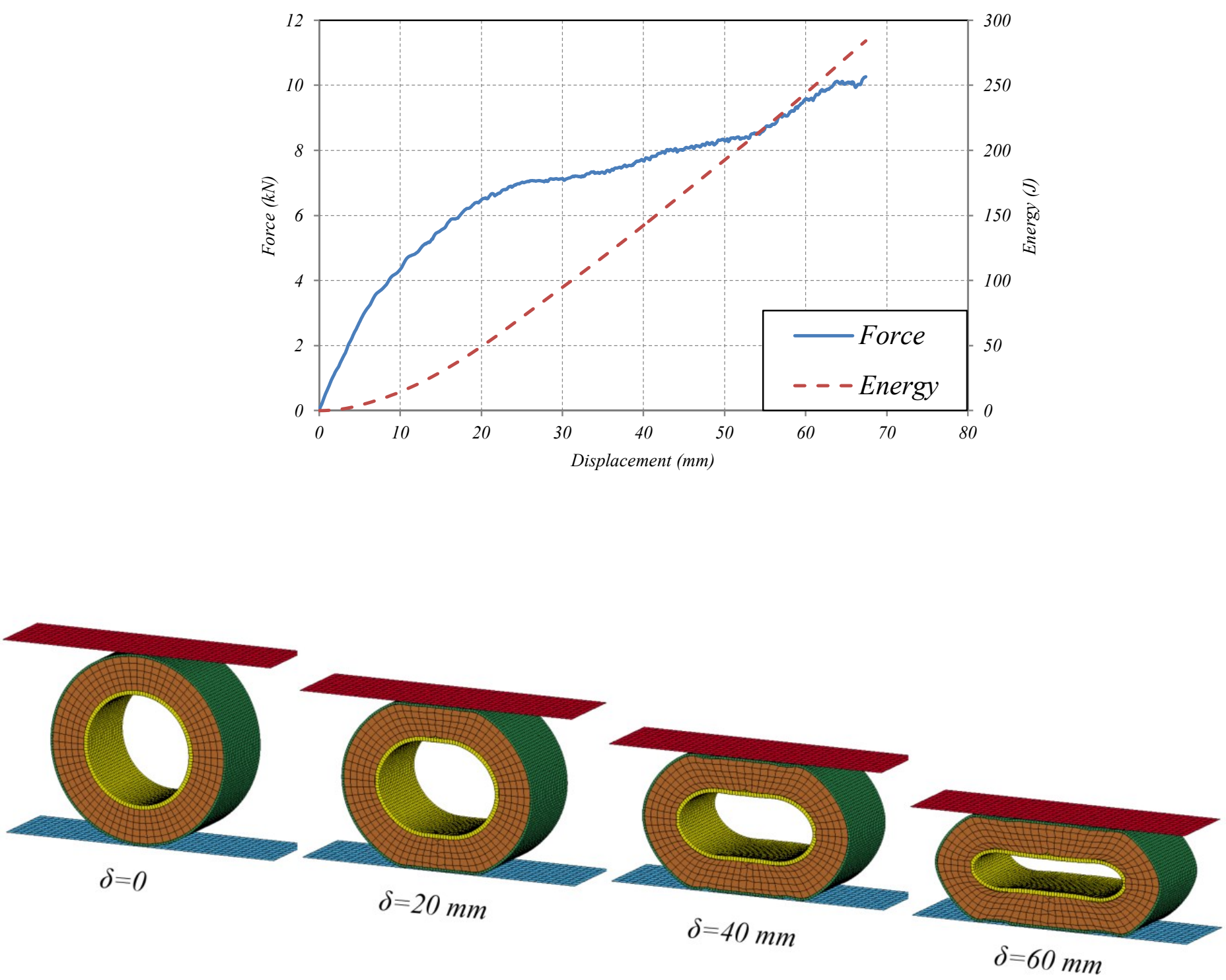
Figure 23: Comparison of optimization results using different solution techniques.

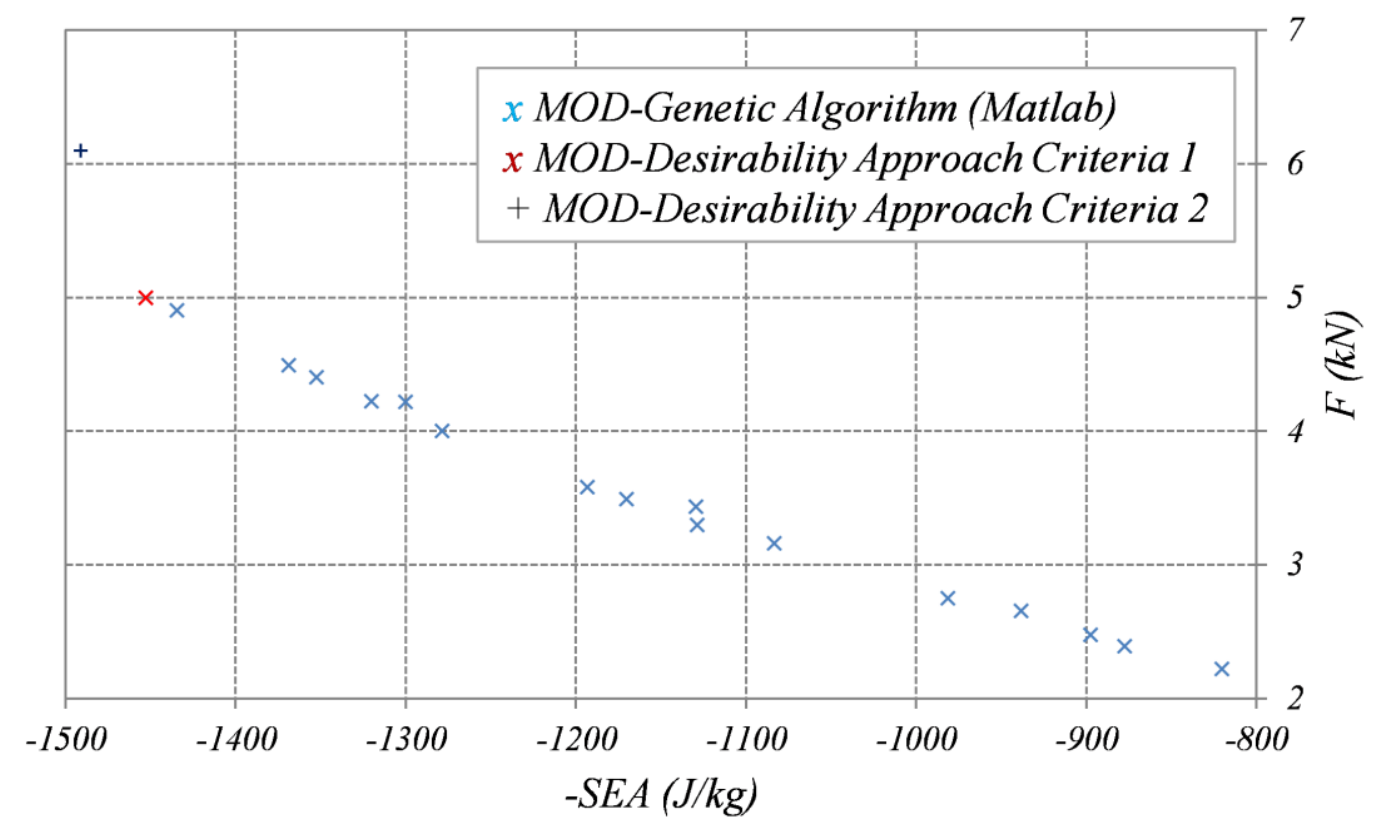


Table 1: Component material properties of the sandwich tubes [30].

\begin{tabular}{|c|c|c|c|c|c|}
\hline & Density (kg/m3) & $\begin{array}{c}\text { Young's } \\
\text { modulus (GPa) }\end{array}$ & Poisson's ratio & $\begin{array}{c}\text { Yield } \\
\text { strength } \\
\text { Rp0.2(MPa) }\end{array}$ & $\begin{array}{l}\text { Hardening } \\
\text { modulus }\end{array}$ \\
\hline AA6060T5 & 2760 & 69 & 0.3 & 150 & 345 \\
\hline ALPORAS $®$ & $230 \pm 20$ & $1.1 \pm 0.1$ & 0.33 & $1.5 \pm 0.1$ & -- \\
\hline
\end{tabular}


Table 2: Independent variables and experimental design levels used.

\begin{tabular}{|c|c|c|c|c|}
\hline Variable & Unit & code & Low & High \\
\hline Outer Diameter(Do) & $m m$ & $A$ & 100 & 150 \\
\hline Outer Thickness(to) & $m m$ & $B$ & 1.5 & 3 \\
\hline Inner Diameter(Di) & $m m$ & $C$ & 80 & 130 \\
\hline Inner Thickness(ti) & $m m$ & $D$ & 1.5 & 3 \\
\hline Constraint & \multicolumn{5}{|c}{$20<=(A-C)<=50$} \\
\end{tabular}


Table 3: The design matrix

\begin{tabular}{|c|c|c|c|c|c|c|}
\hline Run & Do (mm) & to $(\mathrm{mm})$ & Di (mm) & $\mathrm{ti}(\mathrm{mm})$ & SEA $(\mathrm{J} / \mathrm{kg})$ & $F(k N)$ \\
\hline 1 & 131.25 & 1.52 & 100.87 & 2.27 & 924.90 & 3.1 \\
\hline 2 & 130.00 & 1.50 & 80.00 & 3.00 & 1509.93 & 6.3 \\
\hline 3 & 147.35 & 1.50 & 114.88 & 3.00 & 881.89 & 3.1 \\
\hline 4 & 110.94 & 3.00 & 80.00 & 3.00 & 1010.82 & 4.5 \\
\hline 5 & 127.69 & 3.00 & 107.69 & 2.41 & 685.41 & 2.7 \\
\hline 6 & 106.46 & 2.25 & 80.00 & 2.25 & 888.64 & 3.06 \\
\hline 7 & 100.00 & 3.00 & 80.00 & 1.50 & 808.82 & 2.6 \\
\hline 8 & 100.00 & 1.50 & 80.00 & 3.00 & 972.75 & 3 \\
\hline 9 & 110.95 & 1.50 & 80.00 & 1.50 & 1032.76 & 2.9 \\
\hline 10 & 127.68 & 2.09 & 107.68 & 1.50 & 678.06 & 2.05 \\
\hline 11 & 150.00 & 3.00 & 130.00 & 1.50 & 612.96 & 2 \\
\hline 12 & 135.00 & 2.42 & 85.00 & 2.61 & 1258.62 & 5.9 \\
\hline 13 & 150.00 & 2.50 & 130.00 & 3.00 & 622.00 & 2.5 \\
\hline 14 & 150.00 & 3.00 & 100.00 & 3.00 & 1133.28 & 5.6 \\
\hline 15 & 150.00 & 2.31 & 109.77 & 2.19 & 954.32 & 4.3 \\
\hline 16 & 150.00 & 1.50 & 130.00 & 2.00 & 652.33 & 2 \\
\hline 17 & 100.00 & 1.50 & 80.00 & 3.00 & 972.75 & 3 \\
\hline 18 & 150.00 & 1.50 & 130.00 & 2.00 & 536.78 & 2 \\
\hline 19 & 127.68 & 2.09 & 107.68 & 1.50 & 677.02 & 2.1 \\
\hline 20 & 130.00 & 3.00 & 80.00 & 1.50 & 1202.83 & 5.5 \\
\hline 21 & 150.00 & 2.90 & 100.95 & 1.59 & 1124.46 & 5.4 \\
\hline 22 & 131.25 & 2.04 & 81.25 & 1.83 & 1333.07 & 5.5 \\
\hline 23 & 150.00 & 1.50 & 100.00 & 1.50 & 1391.75 & 4.8 \\
\hline 24 & 100.00 & 3.00 & 80.00 & 1.50 & 808.82 & 2.6 \\
\hline 25 & 110.94 & 3.00 & 80.00 & 3.00 & 1010.75 & 4.25 \\
\hline
\end{tabular}


Table 4: Analysis of variance (ANOVA) table for SEA - Quadratic model.

\begin{tabular}{|c|c|c|c|c|}
\hline Source & Sum of Squares & Mean Square & $F$ Value & p-value \\
\hline Model & 1622713.56 & 202839.19 & 175.60 & $<0.0001$ \\
\hline$A-D o(m m)$ & 875175.88 & 875175.88 & 757.65 & $<0.0001$ \\
\hline$B$-to $(\mathrm{mm})$ & 796.55 & 796.55 & 0.69 & 0.4185 \\
\hline$C-D i$ & 1471567.27 & 1471567.27 & 1273.96 & $<0.0001$ \\
\hline$D-t i$ & 11551.44 & 11551.44 & 10.00 & 0.0060 \\
\hline$A B$ & 30315.24 & 30315.24 & 26.24 & 0.0001 \\
\hline$A D$ & 13108.21 & 13108.21 & 11.35 & 0.0039 \\
\hline$B C$ & 34445.05 & 34445.05 & 29.82 & $<0.0001$ \\
\hline$D^{\wedge} 2$ & 10012.94 & 10012.94 & 8.67 & 0.0095 \\
\hline Residual & 18481.83 & 1155.11 & & \\
\hline Cor Total & 1641195.39 & & & \\
\hline & & \multicolumn{3}{|c|}{ Final equation obtained from the model } \\
\hline$R$-Squared & 0.99 & \multicolumn{3}{|c|}{$S E A(J / \mathrm{kg})=+652.89608+31.19174^{*} D o$} \\
\hline Adj R-Squared & 0.98 & \multicolumn{3}{|c|}{$+32.67067 * t o-32.90101 * D i$} \\
\hline Pred R-Squared & 0.97 & \multicolumn{3}{|c|}{$-1.98675^{*} D o^{*} t i+5.27361 * t o * D i$} \\
\hline Adeq Precision & 45.12 & & +90.79922 & \\
\hline
\end{tabular}


Table 5: Analysis of variance (ANOVA) table for F - Quadratic model.

\begin{tabular}{|c|c|c|c|c|}
\hline Source & Sum of Squares & Mean Square & $F$ Value & p-value \\
\hline Model & 0.67685 & 0.13537 & 340.5916 & $<0.0001$ \\
\hline$A-D o(m m)$ & 0.43262 & 0.43262 & 1088.474 & $<0.0001$ \\
\hline$B$-to $(\mathrm{mm})$ & 0.011755 & 0.011755 & 29.57637 & $<0.0001$ \\
\hline$C-D i$ & 0.576157 & 0.576157 & 1449.613 & $<0.0001$ \\
\hline$D-t i$ & 0.036023 & 0.036023 & 90.63353 & $<0.0001$ \\
\hline$A D$ & 0.002751 & 0.002751 & 6.921308 & 0.0165 \\
\hline Residual & 0.007552 & 0.000397 & & \\
\hline Cor Total & 0.684402 & & & \\
\hline & & \multicolumn{3}{|c|}{ Final equation obtained from the model } \\
\hline$R$-Squared & 0.988966 & \multicolumn{3}{|c|}{$\log 10(F)=-0.086641+0.013033 * D o$} \\
\hline Adj R-Squared & 0.986062 & \multicolumn{3}{|c|}{$+0.035153 *$ to } \\
\hline Pred R-Squared & 0.978743 & \multicolumn{3}{|c|}{$+0.16989 * t i$} \\
\hline Adeq Precision & 49.7573 & \multicolumn{3}{|c|}{$-8.66702 E-004 * D o * t i$} \\
\hline
\end{tabular}


Table 6: Optimization criterion 1.

\begin{tabular}{|c|c|c|c|c|c|}
\hline Name & Goal & Limit & Limit & Weight & Importance \\
\hline A:Do $(\mathrm{mm})$ & is in range & 100 & 150 & 1 & 3 \\
\hline B:to $(\mathrm{mm})$ & is in range & 1.5 & 3 & 1 & 3 \\
\hline C:Di $(\mathrm{mm})$ & is in range & 80 & 130 & 1 & 3 \\
\hline D:ti $(\mathrm{mm})$ & is in range & 1.5 & 3 & 1 & 3 \\
\hline SEA $(\mathrm{J} / \mathrm{kg})$ & maximize & 536.7795 & 1509.934 & 10 & 3 \\
\hline$F(\mathrm{kN})$ & minimize & 2 & 6.3 & 1 & 3 \\
\hline
\end{tabular}


Table 7: Optimization criterion 2.

\begin{tabular}{|c|c|c|c|c|c|}
\hline Name & Goal & Limit & Limit & Weight & Importance \\
\hline A:Do $(\mathrm{mm})$ & is in range & 100 & 150 & 1 & 3 \\
\hline B:to $(\mathrm{mm})$ & is in range & 1.5 & 3 & 1 & 3 \\
\hline C:Di $(\mathrm{mm})$ & is in range & 80 & 130 & 1 & 3 \\
\hline D:ti $(\mathrm{mm})$ & is in range & 1.5 & 3 & 1 & 3 \\
\hline SEA $(\mathrm{J} / \mathrm{kg})$ & maximize & 536.7795 & 1509.934 & 10 & 5 \\
\hline$F(\mathrm{kN})$ & minimize & 2 & 6.3 & 1 & 1 \\
\hline
\end{tabular}


Table 8: Optimal solutions as obtained by Design-Expert

\begin{tabular}{|c|c|c|c|c|c|c|c|}
\hline Criterion & Do $(\mathrm{mm})$ & to $(\mathrm{mm})$ & Di $(\mathrm{mm})$ & ti $(\mathrm{mm})$ & SEA $(\mathrm{J} / \mathrm{kg})$ & Force $(\mathrm{kN})$ & Desirability \\
\hline 1 & 130.00 & 1.50 & 80.00 & 1.5 & 1452.557 & 5.00 & 0.405262 \\
\hline 2 & 130.00 & 1.50 & 80.00 & 3.00 & 1491 & 6.09 & 0.515021 \\
\hline
\end{tabular}


Table 9: Confirmation experiments of the optimal solutions.

\begin{tabular}{|c|c|c|c|}
\hline \multirow{4}{*}{ Criteria (1) } & & SEA $(\mathrm{J} / \mathrm{kg})$ & $F(\mathrm{kN})$ \\
\cline { 2 - 4 } & Numerical(FE) & 1483 & 5 \\
\cline { 2 - 4 } & Predicted(RS) & 1452.5 & 5 \\
\hline \multirow{3}{*}{ Criteria (2) } & Error & $2 \%$ & $0 \%$ \\
\cline { 2 - 4 } & Predicted(RS) & 1491 & 6.09 \\
\cline { 2 - 4 } & Error & $1.25 \%$ & $3.33 \%$ \\
\hline
\end{tabular}

